Tecnociencia, Vol. 23, №1:198-237

Enero-Junio 2021

\title{
LISTA SISTEMÁTICA PRELIMINAR DE LOS PECES MARINOS COMERCIALES DEL PACÍFICO DE PANAMÁ
}

\author{
${ }^{1,2}$ Humberto Garcés B. \\ ${ }^{1}$ Universidad de Panamá, Departamento de Biología Marina y Limnología \\ ${ }^{2}$ Estación Científica COIBA (COIBA-AIP), Investigador asociado \\ e-mail: hgarcesb@gmail.com
}

\section{RESUMEN}

Los recursos pesqueros abarcan todavía a un importante sector de la economía panameña, pero se requiere aún de contar con una serie de datos de forma continua y más completa con el fin de contar con una data pesquera confiable. Se presenta por vez primera una lista revisada, actualizada y ordenada filogenéticamente con los peces comerciales que ocurren en la costa Pacífica de la República de Panamá. Para ello se consolidó en una sola lista los tres informes gubernamentales disponibles, así como de otras publicaciones recientes sobre peces comerciales del Pacífico panameño. El listado obtenido fue ordenado filogenéticamente siguiendo a Nelson (2018) e incluye una revisión integral de los nombres científicos actualizados con su respectiva autoridad y año según FishBase (2019), así como los principales nombres comunes utilizados localmente. Se obtuvo un total de 223 especies de peces de importancia comercial para el Pacífico de Panamá, correspondientes a 183 peces óseos y 40 cartilaginosos. Para cada récord consolidado de los peces se incluye en dicha lista el orden $(\mathrm{N}=24)$ y la familia $(\mathrm{N}=49)$, así como la autoridad y año válido para cada uno de los mismos. Las familias más representativas listadas fueron Carangidae (28 carángidos), Sciaenidae (25 corvinas), Carcharhinidae (17 tiburones), Serranidae (17 serránidos), Haemulidae (14 roncadores) y Lutjanidae (10 pargos), comprendiendo un $50 \%$ del total (111 especies). Adicionalmente, se encontraron un total de 31 especies de peces comerciales que ocurren en ambas vertientes de Panamá (Pacífico y Caribe), así como a 39 en alguna categoría de amenaza. Se requiere de un mayor esfuerzo en la captura de datos de los desembarques pesqueros a nivel nacional para poder evaluar el comportamiento y medidas a aplicar para algunas de nuestra s pesquerías comerciales. 
PALABRAS CLAVES: lista provisional, peces comerciales, Pacífico, Panamá.

\title{
PRELIMINARY SYSTEMATIC LIST OF COMMERCIAL MARINE FISHES OF PACIFIC PANAMA
}

\begin{abstract}
Panamanian fishery resources still cover an important economic sector, but it still requires a more complete and continuos data series in order to count on a reliable fishing data. A revised, updated and phylogenetically ordered list is presented for the first time with the commercial fishes that occurs on the Pacific coast of the Republic of Panama. For this, the three available government reports, as well as other recent publications on commercial fish from the Panamanian Pacific, were consolidated into a single list. The obtained list was phylogenetically ordered following Nelson (2018) and included a comprehensive review of the updated scientific names with their respective authority and year according to FishBase (2019), as well as the main common names used locally. A total of 223 commercial fish species for the Pacific of Panama were obtained, corresponding to 183 bony and 40 cartilaginous fish. For each consolidated fish record, the order $(\mathrm{N}=24)$ and the family $(\mathrm{N}=49)$ are included in this list, as well as the authority and valid year for each of them. The most representative families listed were Carangidae (28 jacks), Sciaenidae (25 croakers), Carcharhinidae (17 sharks), Serranidae (17 groupers), Haemulidae (14 grunts), and Lutjanidae (10 snappers), comprising $50 \%$ of the total (111 species). Additionally, a total of 31 commercial fish species were found that occurs on both slopes of Panama (Pacific and Caribbean), as well as 39 under some threat category. A greater effort is required in capturing data on fishing landings at the national level in order to evaluate the behavior and measures to be applied for some of our commercial fisheries.
\end{abstract}

KEY WORDS: provisional list, commercial fisheries, Pacific, Panama.

\section{INTRODUCCIÓN}

La República de Panamá posee un territorio marítimo con una superficie de $319823,9 \mathrm{~km}^{2}$ versus una superficie total emergida de 75 $517,0 \mathrm{~km}^{2}$ y contando con 1518 islas (495 en el Pacífico), islotes y cayos. El país posee una importante longitud de sus costas que comprenden un total de $2988,3 \mathrm{~km}, 1700,6 \mathrm{~km}$ corresponden al litoral Pacífico (Arenas \& Garcés, 2009; Garcés, 2014; CONTRALORÍA GENERAL DE LA REPÚBLICA, 2019). Los recursos marino- 
costeros se redefinen en la Ley No. 8 que crea al Ministerio del Ambiente (MiAmbiente) y podemos indicar que son aquellos que se encuentran en las aguas del mar territorial, los esteros, la plataforma continental submarina, los litorales, las bahías y los estuarios. Así como también en los manglares, los arrecifes y en la vegetación submarina e incluyen los recursos bióticos y abióticos dentro de dichas aguas. Incluye también aquellos recursos naturales renovables encontrados en una franja costera de $200 \mathrm{~m}$ de ancho de la línea de la pleamar, paralela al litoral de las costas del mar Caribe y del Océano Pacífico, con excepción de los recursos minerales e hidrocarburos (MIAMBIENTE, 2015; ARAP, 2019a).

Para la economía de Panamá es de suma importancia la pesca industrial, artesanal y deportiva e industria del ecoturismo que se ejercen sobre diversos recursos marinos y costeros. Dichas industrias pesqueras aportan a la economía tanto en valores de producción como en generación de empleos en forma directa e indirecta, estimándose en unos 32000 pescadores (OSPESCA, 2012). La pesca industrial ha generado en promedio unos 225,8 millones de balboas entre 19992012, mientras que la cantidad de pesca total anual promedio es de unos $184,0 \times 10^{3}$ toneladas métricas o TM. Las principales especies de peces capturadas en la pesca industrial son anchovetas, arenques, atunes, orquetas y tiburones (CONTRALORÍA GENERAL DE LA REPÚBLICA, 2019).

La pesca artesanal es de suma importancia para nuestro país ya que aporta a la economía tanto en generación de empleos, en forma directa e indirecta, como en valores de producción generado en promedio unos 59,1 millones de balboas entre 1999-2012, mientras que la cantidad de pesca total anual promedio es de unos $26,6 \times 10^{3} \mathrm{TM}$. Las principales especies capturadas de peces en la pesca artesanal son pargos, corvinas, sierras y cojinúas. Vale destacar que, aunque la cantidad y valor del desembarque anual de la pesca industrial y artesanal ha sido muy fluctuante en todos sus valores promedios en los últimos 15 años 
(Garcés, 2014; CONTRALORÍA GENERAL DE LA REPÚBLICA, 2019).

La información sobre la pesca artesanal de carácter comercial ha provenido principalmente de las organizaciones de pescadores que se fundaron en base a proyectos administrados por la Dirección General de Recursos Marinos y Costeros de la AMP (Justines, 2000). Aun en la actualidad, no se cuenta con una plataforma eficiente para la toma de datos de los desembarques pesqueros en forma generalizada, ésta se lleva a cabo de manera discontinua e incompleta, situación que no permite la acumulación de data necesaria que permita la toma de decisiones (AMP, 2005). Es importante recopilar datos e información confiable sobre las especies de interés comercial que llegan al mercado del marisco, de forma tal que los mismos sirvan para tomar decisiones correctas referentes a la ordenación pesquera en nuestro país.

Existen estadísticas pesqueras que contiene una lista de algunas especies marinas de importancia comercial de Panamá (MICI, 1977 y 1992). Mas recientemente existe un folleto con estadística pesquera con una lista de algunas especies de importancia comercial (AMP, 2005). En todas estas listas se incluyen peces óseos y tiburones con diferentes nombres comunes, así como específicos incluyendo especies del Atlántico (o Caribe) de Panamá e incluyen aquellas especies objetivo propias de la pesca artesanal, industrial o deportiva.

Para Panamá se conoce que existen un gran total de 1,412 especies de peces informadas de los cuales 1,240 son marinos (FISHBASE, 2019). Por otro lado, la ARAP informa que en Panamá existen un total de 1,242 especies de peces marinos, de los cuales 678 son del Pacífico e incluyen 65 especies que ocurren en ambos océanos. De éstos solamente se reconocen que existen 140 especies de peces de importancia comercial para ambos océanos (ARAP, 2019b).

El análisis histórico e institucional del sector pesquero en Panamá se encuentra bastante bien documentando incluyendo al subsector artesanal (Meneses, 2000). También se cuenta con la información muy 
preocupante de que muy posiblemente el valor de las capturas pesqueras en Panamá está muy subestimado y rondan el orden de hasta 92 millones anuales (Cisneros-Montemayor et al., 2018). Vale destacar que el análisis correlacional de los informes pesqueros disponibles indica que son insuficientes para estimar la producción artesanal $\left(\mathrm{R}^{2}=\right.$ 0.2265) para el período 2000-2008 (Valverde, 2013).

Las especies de peces del Pacífico oriental tropical han sido bastante bien definidas en diferentes tipos de publicaciones disponibles (Allen \& Robertson, 1998; Garrison, 2005; Bussing \& López, 2011; ARAP, 2011; Robertson \& Allen, 2006, 2015 y 2016; MARVIVA, 2017). Por otro lado, las principales especies de peces capturadas en la pesca artesanal se reportan de forma general siendo las principales especies capturadas los pargos, corvinas, sierras y cojinúas, entre otros (AMP, 2005). No obstante, no existe un listado actualizado que contenga a las principales especies de peces que se comercializan actualmente en el Pacífico de Panamá.

El propósito de esta investigación fue el obtener una lista sistemática actualizada con todas las especies de peces comerciales reportadas $u$ observadas que ocurren en el Pacífico de Panamá.

\section{MATERIALES Y MÉTODOS}

La elaboración del listado de peces comerciales del Pacífico de Panamá se realizó a partir de la información contenida en los tres listados gubernamentales existentes con las especies de importancia comercial (MICI, 1977 y 1992; AMP, 2005). Adicionalmente, se verificaron y adicionaron las especies de peces comerciales contenidas en publicaciones recientes (Justines, 2000; ARAP, 2011; MARVIVA, 2017). Por último, se incluyen aquellas especies y nombres comunes verificados por el autor principalmente en el Mercado del Marisco (Garcés, 2018), así como en los puertos Panamá, Juan Díaz y Coquira en los últimos 10 años. 
Todas las especies de peces listadas se verificaron taxonómicamente en base al catálogo mundial de especies (FISHBASE, 2019), así como con la ayuda de otras publicaciones ictiológicas disponibles (Fischer et al., 1995; Allen \& Robertson, 1998; Robertson \& Allen, 2015 y 2016). La verificación de todos los nombres científicos, autoridad y año sigue lo establecido en Fishbase (2019) y se excluyen aquellos registros de dudosa determinación taxonómica o bien de distribución. El listado de peces comerciales se ordenó sistemáticamente por órdenes y familias según Nelson (2018), los géneros y especies dentro de cada familia se arreglaron alfabéticamente.

Para todos los registros se incluyó si se trata de una actualización menor $(+)$ ya sea en la referencia de la autoridad y/o año o bien en la escritura del nombre específico, o de una actualización mayor (*) normalmente en el género (sinonimia). Las actualizaciones mayores se refieren a cambios recientes en la nomenclatura de los nombres específicos, normalmente en los géneros relegando los registros originales a sinonimia. Para todos los registros se incluyeron las referencias bibliográficas con los listados y publicaciones ictiológicas más relevantes, incluyendo el de observaciones por el autor.

El listado preliminar incluye una revisión de aquellos registros de peces marinos comerciales que se encuentran en ambas vertientes, denotándolas como $(\mathrm{P}, \mathrm{C})$, Pacífico y Caribe (o Atlántico), después de la autoridad. Se incluyen también aquellas especies que aparecen en la lista de vulnerables (VU) a nivel internacional (FISHBASE, 2019). Por último, se adiciona al listado la condición relativa de especie comercial, ubicándola como menor $\left(\mathrm{Co}^{*}\right)$ o mayor $(\mathrm{Co} * *)$ en observaciones.

\section{RESULTADOS Y DISCUSIÓN}

A continuación, haremos una breve descripción de los principales hallazgos que encontramos en los tres listados que contienen especies de peces de importancia comercial del Pacífico de Panamá disponibles, así como en otras tres publicaciones relacionadas. 


\section{Estadísticas Pesqueras del MICI (1977).}

Este listado fue realizado por la Dirección General de Recursos Marinos del Ministerio de Comercio e Industrias para el período de 1968 a 1977. Se informan de un total de 120 especies marinas de importancia comercial que incluyen 92 peces comerciales, 82 óseos y 10 cartilaginosos. Este listado incluye el caballito (Selene vomer) y la cojinúa (Caranx chrysos) del Atlántico (o Caribe), así como la panchita sin especificar especie y el sargento (Cichla ocellaris) el cual es un pez dulceacuícola exótico.

\section{Estadísticas Pesqueras del MICI (1992).}

En este listado de la Dirección General de Recursos Marinos del Ministerio de Comercio e Industrias se incluye data para el período de 1981 a 1990. Se informan de un total de 206 especies marinas de importancia comercial que incluyen 152 peces comerciales, 140 óseos y 12 cartilaginosos. Especies comerciales reportadas que ocurren en el Caribe fueron arenque (Opisthonema oglinum), bojalá (Seriola dumerilii), caballito (Selene vomer), cojinúa (Caranx chrysos), macabí (Elops saurus), pargo de la mancha (Lutjanus cyanopterus), róbalos (Centropomus undecimalis y C. poeyi) y sierra (Scomberomorus maculatus). Por otro lado, especies que ocurren en ambos océanos fueron pámpano africano (Alectis crinitus $=$ A . ciliaris), bojalá (Seriola rivoliana), macabí (Albula vulpes), salmón (Elegatis bipinnulatus), tiburón gata (Ginglymostuma cirratum) y tiburón tigre (Galeocerdo cuvier).

\section{Estadísticas Pesqueras de AMP (2005).}

Este listado fue realizado por la Dirección General de Recursos Marinos y Costeros de la Autoridad Marítima de Panamá para el período de 2000 al 2004. Se informan de un total de 121 especies marinas de importancia comercial que incluyen 80 peces, 74 óseos y seis (6) cartilaginosos. Especies de peces comerciales reportadas que ocurren en el Caribe fueron arenque (Opisthonema oglinum), bojalá 
(Seriola dumerilii), caballito (Selene vomer) y cojinúa (Caranx chrysos).

\section{Otras publicaciones revisadas.}

$\mathrm{Se}$ revisaron las especies comerciales informadas en diversas publicaciones disponibles, principalmente el folleto con los principales recursos pesqueros de Justines (2000) y las guías para la identificación de peces de la ARAP (2011) y la de MarViva (2017). El folleto de Justines informa de un total de 58 especies de peces comerciales separándolas por los diferentes tipos de pesquerías que se dan a nivel nacional. Por otro lado, la guía de campo de ARAP contiene 138 especies de peces de interés comercial encontrados en el Pacífico. Por último, la guía de identificación de MarViva contiene 157 especies de peces de importancia comercial del Pacífico de Panamá.

En el listado consolidado de peces comerciales del Pacífico se revisaron y actualizaron los nombres comunes en español que aparecen en los tres informes y que fueran de uso local conocido (Garcés, 2018). También se revisaron y actualizaron todos los nombres científicos dando por vez primera un listado ordenado filogenéticamente por órdenes y familias, así como la autoridad y año y actualizando la distribución Pacífico-Caribe informada (FishBase, 2019). Vale destacar que las principales autoridades con nombres válidos de peces comerciales para Panamá (No. registros) incluyen a Jordan \& Gilbert, 1882 (18), Günther, 1864 (15), Gill, 1863 (12), Steindachner, 1876 (12), Gill, 1862 (11), Linnaeus (L.), 1758 (8), Günther, 1867 (6) y Gilbert, 1898 (6), para un total de 88 registros.

El listado consolidado con las especies de peces de importancia comercial correspondientes a la costa Pacífica de Panamá incluye un total de 223 especies de peces, 183 óseos y 40 cartilaginosos (ver Cuadro No. 1). Dichas 223 especies de peces se ubican en un total de 24 órdenes, 49 familias y 121 géneros. Las familias de peces más representativas del listado fueron Carangidae (28 carángidos), Sciaenidae (25 corvinas), Carcharhinidae (17 tiburones), Serranidae (17 meros y chernas), Haemulidae (14 roncadores), Lutjanidae (10 
pargos), Ariidae (8 bagres), Scombridae (8 atunes) y Paralichthyidae (8 lenguados), para un total de 135 especies $(61 \%$ del total). Los géneros más representados en los listados fueron los tiburones Carcharhinus spp. (11), los pargos Lutjanus spp. (9), los martillos Sphyrna spp. (6), jureles y cojinúas Caranx spp. (6), los róbalos Centropomus spp. (6) y las corvinas Cynoscion spp. (6).

Con este listado se actualiza la gran mayoría de los nombres científicos incluyendo las autoridades para 130 registros de peces de importancia comercial del Pacífico de Panamá, exceptuando la mojarra Diapterus peruvianus $(=D$. brevirostris). De igual forma se establecen los principales nombres comunes comerciales locales correspondientes al área de estudio, no se incluyen algunos de los nombres comunes propios del golfo de Chiriquí (Maté, 2007). Vale destacar que nuestro listado actualiza en 205 los registros de peces de importancia comercial del Pacífico de Panamá (FISHBASE, 2019), incluyendo 31 que ocurren en ambas vertientes (Pacífico, Caribe).

Del listado obtenido se tendrían aún que verificar la comercialización de algunas especies conocidas de tiburones y rayas, bagres y barbudos, carángidos, lenguados, atunes, meros y chernas y corvinas, exceptuando corvinata (tiburones y/o bagres). Vale destacar, que el tiburón Isurus paucus y los atunes Euthynnus affinis, Thunnus alalunga y $T$. obesus no cuentan todavía con un registro para el Pacífico de Panamá y no fueron incluidos en este listado. Por último, se ubican allí al menos 14 especies vulnerables (FISHBASE, 2019), así como otras 25 en categoría de consumo no recomendado (MARVIVA, 2019), totalizando 39 principalmente tiburones, rayas, picudos y loros. 
Cuadro 1 Listado filogenético con las especies de peces comerciales del Pacífico de Panamá. [P, C; VU]: Pacífico, Caribe, Vulnerable. Referencia: 1:MICI, 1977; 2:MICI, 1992; 3:AMP, 2005; 4:Justines, 2000; 5:ARAP, 2011; 6:MarViva, 2017, 7:este estudio. Obs. comercial menor*/mayor**

\begin{tabular}{|c|c|c|c|c|}
\hline Orden/Familia & $\begin{array}{c}\text { Nombre } \\
\text { científico - } \\
\text { Autoridad [ ] }\end{array}$ & $\begin{array}{l}\text { Nombre } \\
\text { común }\end{array}$ & Referencias & Obs. \\
\hline \multicolumn{5}{|l|}{ Orectolobiformes } \\
\hline \multirow[t]{2}{*}{ Ginglymostidae } & $\begin{array}{c}\text { Ginglymostoma } \\
\text { cirratum } \\
\text { (Bonnaterre, } \\
1788)+[\mathrm{P}, \mathrm{C}]\end{array}$ & $\begin{array}{c}\text { Tiburón gata, } \\
\text { gata }\end{array}$ & $2,3,5$ & $\mathrm{Co}^{*}$ \\
\hline & $\begin{array}{c}\text { Ginglymostoma } \\
\text { unami } \\
\text { (Del Moral- } \\
\text { Flores, } \\
\text { Ramírez- } \\
\text { Antonio, } \\
\text { Angulo y } \\
\text { Pérez-Ponce de } \\
\text { León, 2015) }\end{array}$ & $\begin{array}{c}\text { Tiburón gata, } \\
\text { tiburón } \\
\text { nodriza }\end{array}$ & 6 & $\mathrm{Co}^{*}$ \\
\hline \multicolumn{5}{|l|}{ Lamniformes } \\
\hline \multirow[t]{3}{*}{ Alopiidae } & $\begin{array}{c}\text { Alopias } \\
\text { pelagicus } \\
\text { Nakamura, } \\
1935+[\mathrm{VU}]\end{array}$ & $\begin{array}{l}\text { Tiburón } \\
\text { zorro } \\
\text { pelágico }\end{array}$ & 6 & $\mathrm{Co}^{*}$ \\
\hline & $\begin{array}{c}\text { Alopias } \\
\text { superciliosus } \\
\text { Lowe, } 1841+ \\
\text { [VU] }\end{array}$ & $\begin{array}{l}\text { Tiburón } \\
\text { zorro ojón }\end{array}$ & 6 & $\mathrm{Co}^{*}$ \\
\hline & $\begin{array}{c}\text { Alopias } \\
\text { vulpinus } \\
\text { (Bonnaterre, } \\
\text { 1788) [VU] }\end{array}$ & $\begin{array}{l}\text { Tiburón } \\
\text { zorro cola } \\
\text { delgada }\end{array}$ & 6 & $\mathrm{Co}^{*}$ \\
\hline Lamnidae & $\begin{array}{c}\text { Isurus } \\
\text { oxyrinchus } \\
\text { Rafinesque, } \\
1810+[\mathrm{P}, \mathrm{C}]\end{array}$ & $\begin{array}{l}\text { Tiburón } \\
\text { mako }\end{array}$ & 6 & $\mathrm{Co}^{*}$ \\
\hline
\end{tabular}




\begin{tabular}{|c|c|c|c|c|}
\hline Orden/Familia & $\begin{array}{c}\text { Nombre } \\
\text { científico - } \\
\text { Autoridad [ ] }\end{array}$ & $\begin{array}{l}\text { Nombre } \\
\text { común }\end{array}$ & Referencias & Obs. \\
\hline \multicolumn{5}{|l|}{ Carcharhiniformes } \\
\hline \multirow[t]{3}{*}{ Triakidae } & $\begin{array}{c}\text { Mustelus } \\
\text { dorsalis } \\
\text { Gill, 1864+ }\end{array}$ & $\begin{array}{l}\text { Tiburón } \\
\text { marrón }\end{array}$ & 2 & $\mathrm{Co}^{*}$ \\
\hline & $\begin{array}{c}\text { Mustelus henlei } \\
\text { (Gill, 1863) }\end{array}$ & $\begin{array}{c}\text { Tiburón } \\
\text { mamón, ají }\end{array}$ & 2,6 & $\mathrm{Co}^{*}$ \\
\hline & $\begin{array}{c}\text { Mustelus } \\
\text { lunulatus } \\
\text { Jordan y } \\
\text { Gilbert, 1882+ }\end{array}$ & $\begin{array}{l}\text { Tiburón } \\
\text { mamón, ají }\end{array}$ & $2,4,6,7$ & $\mathrm{Co}^{* *}$ \\
\hline \multirow[t]{6}{*}{ Carcharhinidae } & $\begin{array}{c}\text { Carcharhinus } \\
\text { albimarginatus } \\
\text { (Rüppell, 1837) } \\
{[\mathrm{VU}]}\end{array}$ & \begin{tabular}{|c} 
Tiburón \\
punta blanca, \\
tiburón \\
puntiblanco
\end{tabular} & $4,6,7$ & $\mathrm{Co}^{*}$ \\
\hline & $\begin{array}{l}\text { Carcharhinus } \\
\text { altimus } \\
\text { (Springer, } \\
1950)+[\mathrm{P}, \mathrm{C}]\end{array}$ & $\begin{array}{l}\text { Tiburón } \\
\text { baboso }\end{array}$ & 4 & $\mathrm{Co}^{*}$ \\
\hline & $\begin{array}{l}\text { Carcharhinus } \\
\text { cerdale } \\
\text { Gilbert, } 1898+\end{array}$ & $\begin{array}{c}\text { Tiburón } \\
\text { (toyo) }\end{array}$ & 1 & $\mathrm{Co}^{*}$ \\
\hline & $\begin{array}{c}\text { Carcharhinus } \\
\text { falciformis } \\
\text { (Müller y } \\
\text { Henle, 1839) } \\
\text { [P, C; VU] }\end{array}$ & $\begin{array}{l}\text { Tiburón } \\
\text { tollo, tiburón } \\
\text { sedoso }\end{array}$ & 4,6 & $\mathrm{Co}^{*}$ \\
\hline & $\begin{array}{l}\text { Carcharhinus } \\
\text { galapagensis } \\
\text { (Snodgrass y } \\
\text { Heller, 1905) }\end{array}$ & $\begin{array}{l}\text { Tiburón } \\
\text { blanco }\end{array}$ & 5,6 & $\mathrm{Co}^{*}$ \\
\hline & $\begin{array}{c}\text { Carcharhinus } \\
\text { leucas (Müller } \\
\text { y Henle, 1839) } \\
{[\mathrm{P}, \mathrm{C}]}\end{array}$ & Tiburón toro & 4,6 & $\mathrm{Co}^{*}$ \\
\hline
\end{tabular}




\begin{tabular}{|c|c|c|c|c|}
\hline Orden/Familia & $\begin{array}{c}\text { Nombre } \\
\text { científico - } \\
\text { Autoridad [ ] }\end{array}$ & $\begin{array}{c}\text { Nombre } \\
\text { común }\end{array}$ & Referencias & Obs. \\
\hline & $\begin{array}{c}\text { Carcharhinus } \\
\text { limbatus } \\
\text { (Müller y } \\
\text { Henle, 1839) } \\
{[\mathrm{P}, \mathrm{C}]} \\
\end{array}$ & $\begin{array}{l}\text { Tiburón } \\
\text { aletinegro, } \\
\text { tiburón } \\
\text { puntinegro }\end{array}$ & 1 a 7 & $\mathrm{Co}^{* *}$ \\
\hline & $\begin{array}{c}\text { Carcharhinus } \\
\text { longimanus } \\
\text { (Poey, 1861) } \\
\text { [P, C; VU] }\end{array}$ & $\begin{array}{c}\text { Tiburón } \\
\text { aliblanco, } \\
\text { tiburón punta } \\
\text { blanca } \\
\text { oceánico }\end{array}$ & 6 & $\mathrm{Co}^{*}$ \\
\hline & $\begin{array}{c}\text { Carcharhinus } \\
\text { obscurus } \\
\text { (Lesueur, } \\
1818)+[\mathrm{P}, \mathrm{C}]\end{array}$ & Tiburón café & 1,4 & $\mathrm{Co}^{*}$ \\
\hline & $\begin{array}{c}\text { Carcharhinus } \\
\text { plumbeus } \\
(\mathrm{Nardo}, 1827)^{*} \\
{[\mathrm{P}, \mathrm{C} ; \mathrm{VU}]}\end{array}$ & $\begin{array}{l}\text { Tiburón } \\
\text { (toyo) }\end{array}$ & 1 & $\mathrm{Co}^{*}$ \\
\hline & $\begin{array}{c}\text { Carcharhinus } \\
\text { porosus } \\
\text { (Ranzani, 1839) } \\
{[\mathrm{P}, \mathrm{C}]}\end{array}$ & $\begin{array}{l}\text { Tiburón } \\
\text { cuero, } \\
\text { tiburón } \\
\text { poroso }\end{array}$ & $2,5,6$ & $\mathrm{Co}^{* *}$ \\
\hline & $\begin{array}{c}\text { Galeocerdo } \\
\text { cuvier (Péron y } \\
\text { Lesueur, 1822) } \\
{[\mathrm{P}, \mathrm{C}]}\end{array}$ & $\begin{array}{l}\text { Tiburón } \\
\text { tigre, tiburón } \\
\text { redondo, } \\
\text { tintorera }\end{array}$ & $1,2,3,4,6$ & $\mathrm{Co}^{* *}$ \\
\hline & $\begin{array}{c}\text { Nasolamia } \\
\text { velox (Gilbert, } \\
1898) \\
\end{array}$ & $\begin{array}{c}\text { Tiburón pico } \\
\text { blanco, } \\
\text { torpedo }\end{array}$ & 1,6 & $\mathrm{Co}^{*}$ \\
\hline & $\begin{array}{c}\text { Negaprion } \\
\text { brevirostris } \\
\text { (Poey, 1868) } \\
{[\mathrm{P}, \mathrm{C}]}\end{array}$ & $\begin{array}{l}\text { Tiburón } \\
\text { limón }\end{array}$ & 4,6 & $\mathrm{Co}^{*}$ \\
\hline & $\begin{array}{c}\text { Prionace } \\
\text { glauca }(\mathrm{L} ., \\
1758)[\mathrm{P}, \mathrm{C}]\end{array}$ & Tiburón azul & 3,6 & $\mathrm{Co}^{*}$ \\
\hline
\end{tabular}




\begin{tabular}{|c|c|c|c|c|}
\hline Orden/Familia & $\begin{array}{c}\text { Nombre } \\
\text { científico - } \\
\text { Autoridad [ ] }\end{array}$ & $\begin{array}{l}\text { Nombre } \\
\text { común }\end{array}$ & Referencias & Obs. \\
\hline & $\begin{array}{c}\text { Rhizoprionodon } \\
\text { longurio } \\
\text { (Jordan y } \\
\text { Gilbert, 1882) }\end{array}$ & $\begin{array}{l}\text { Tiburón } \\
\text { cueriduro, } \\
\text { tiburón } \\
\text { picudo }\end{array}$ & $1,2,4,5,6$ & $\mathrm{Co}^{* *}$ \\
\hline & $\begin{array}{c}\text { Triaenodon } \\
\text { obesus (Rüppel, } \\
1837 \text { ) }\end{array}$ & $\begin{array}{c}\text { Tiburón } \\
\text { aliblanco, } \\
\text { punta blanca }\end{array}$ & 6 & $\mathrm{Co}^{*}$ \\
\hline \multirow[t]{6}{*}{ Sphyrnidae } & $\begin{array}{c}\text { Sphyrna corona } \\
\text { Springer, } \\
1940+\end{array}$ & $\begin{array}{l}\text { Tiburón } \\
\text { martillo, } \\
\text { gorrua, } \\
\text { paletita } \\
\text { amarilla }\end{array}$ & $2,5,6$ & $\mathrm{Co}^{* *}$ \\
\hline & $\begin{array}{c}\text { Sphyrna lewini } \\
\text { (Griffith y } \\
\text { Smith, 1834) } \\
\text { [P, C; VU] }\end{array}$ & $\begin{array}{l}\text { Tiburón } \\
\text { martillo, } \\
\text { gorrua, } \\
\text { cornuda } \\
\text { común }\end{array}$ & 1 a 7 & $\mathrm{Co}^{* *}$ \\
\hline & $\begin{array}{c}\text { Sphyrna media } \\
\text { Springer, } \\
1940+\end{array}$ & $\begin{array}{l}\text { Tiburón } \\
\text { martillo, } \\
\text { gorrua, } \\
\text { tiburón } \\
\text { cuchara }\end{array}$ & $4,5,6$ & $\mathrm{Co}^{* *}$ \\
\hline & $\begin{array}{c}\text { Sphyrna } \\
\text { mokarran } \\
\text { (Rüppell, 1837) } \\
{[\mathrm{P}, \mathrm{C} ; \mathrm{VU}]}\end{array}$ & $\begin{array}{c}\text { Tiburón } \\
\text { martillo, } \\
\text { gorrua }\end{array}$ & 6 & $\mathrm{Co}^{*}$ \\
\hline & $\begin{array}{l}\text { Sphyrna tiburo } \\
\text { (L., 1758) }\end{array}$ & $\begin{array}{l}\text { Tiburón } \\
\text { martillo, } \\
\text { gorrua, } \\
\text { tiburón pala }\end{array}$ & $1,2,5,6$ & $\mathrm{Co}^{* *}$ \\
\hline & $\begin{array}{c}\text { Sphyrna } \\
\text { zygaena } \\
\text { (L., 1758) } \\
\text { [VU] }\end{array}$ & $\begin{array}{l}\text { Tiburón } \\
\text { martillo, } \\
\text { gorrua }\end{array}$ & 6 & $\mathrm{Co}^{*}$ \\
\hline
\end{tabular}




\begin{tabular}{|c|c|c|c|c|}
\hline Orden/Familia & $\begin{array}{c}\text { Nombre } \\
\text { científico - } \\
\text { Autoridad [ ] }\end{array}$ & $\begin{array}{l}\text { Nombre } \\
\text { común }\end{array}$ & Referencias & Obs. \\
\hline \multicolumn{5}{|l|}{ Torpediniformes } \\
\hline Narcinidae & $\begin{array}{c}\text { Narcine } \\
\text { entemedor } \\
\text { Jordan y Starks, } \\
1895+\end{array}$ & $\begin{array}{l}\text { Raya } \\
\text { eléctrica }\end{array}$ & 5 & $\mathrm{Co}^{*}$ \\
\hline \multicolumn{5}{|l|}{ Pristiformes } \\
\hline \multirow[t]{2}{*}{ Rhinobatidae } & $\begin{array}{l}\text { Pseudobatos } \\
\text { leucorhynchus } \\
\text { (Günther, } \\
\text { 1867)* }\end{array}$ & $\begin{array}{l}\text { Raya } \\
\text { guitarra, } \\
\text { guitarra }\end{array}$ & 5,6 & $\mathrm{Co}^{*}$ \\
\hline & $\begin{array}{c}\text { Zapteryx xyster } \\
\text { Jordan y } \\
\text { Evermann, } \\
1896+ \\
\end{array}$ & $\begin{array}{c}\text { Guitarra } \\
\text { bruja }\end{array}$ & 5 & $\mathrm{Co}^{*}$ \\
\hline \multicolumn{5}{|l|}{ Myliobatiformes } \\
\hline \multirow[t]{3}{*}{ Dasyatidae } & $\begin{array}{c}\text { Hypanus } \\
\text { dipterurus } \\
\text { (Jordan y } \\
\text { Gilbert, 1880)* }\end{array}$ & $\begin{array}{l}\text { Raya látigo } \\
\text { diamante }\end{array}$ & 5,6 & $\mathrm{Co}^{*}$ \\
\hline & $\begin{array}{l}\text { Hypanus longus } \\
\text { (Garman, } \\
1880)^{*}\end{array}$ & Raya látigo & 5,6 & $\mathrm{Co}^{*}$ \\
\hline & $\begin{array}{c}\text { Pteroplatytrygo } \\
n \text { violacea } \\
\text { (Bonaparte, } \\
1832 \text { ) } \\
\end{array}$ & Raya látigo & 6 & $\mathrm{Co}^{*}$ \\
\hline Urotrygonidae & $\begin{array}{c}\text { Urotrygon } \\
\text { aspidura } \\
\text { (Jordan y } \\
\text { Gilbert, 1882)+ }\end{array}$ & $\begin{array}{c}\text { Raya } \\
\text { redonda }\end{array}$ & 5 & $\mathrm{Co}^{*}$ \\
\hline Myliobatidae & $\begin{array}{c}\text { Aetobatus } \\
\text { laticeps Gill, } \\
1865\end{array}$ & $\begin{array}{c}\text { Raya } \\
\text { manchada, } \\
\text { chucho } \\
\text { pintado, } \\
\text { maya }\end{array}$ & 5,6 & $\mathrm{Co}^{*}$ \\
\hline
\end{tabular}




\begin{tabular}{|c|c|c|c|c|}
\hline Orden/Familia & $\begin{array}{c}\text { Nombre } \\
\text { científico - } \\
\text { Autoridad [ ] }\end{array}$ & $\begin{array}{l}\text { Nombre } \\
\text { común }\end{array}$ & Referencias & Obs. \\
\hline \multicolumn{5}{|l|}{ Elopiformes } \\
\hline Elopidae & $\begin{array}{l}\text { Elops affinis } \\
\text { Regan, 1909+ }\end{array}$ & Macabí & 2,6 & $\mathrm{Co}^{*}$ \\
\hline Megalopidae & $\begin{array}{c}\text { Megalops } \\
\text { atlanticus } \\
\text { Valenciennes, } \\
1847+ \\
{[\mathrm{P}, \mathrm{C} ; \mathrm{VU}]}\end{array}$ & $\begin{array}{l}\text { Sábalo, } \\
\text { sábalo real }\end{array}$ & 6 & $\mathrm{Co}^{*}$ \\
\hline \multicolumn{5}{|l|}{ Albuliformes } \\
\hline \multirow[t]{3}{*}{ Albulidae } & $\begin{array}{c}\text { Albula esuncula } \\
\text { (Garman, } \\
1899)+\end{array}$ & Macabí & 5 & $\mathrm{Co}^{*}$ \\
\hline & $\begin{array}{l}\text { Albula pacifica } \\
\text { (Beebe, 1942)+ }\end{array}$ & $\begin{array}{c}\text { Zorro de } \\
\text { hebra }\end{array}$ & 5 & $\mathrm{Co}^{*}$ \\
\hline & $\begin{array}{c}\text { Albula vulpes } \\
(\mathrm{L} ., 1758)+ \\
{[\mathrm{P}, \mathrm{C}]}\end{array}$ & $\begin{array}{l}\text { Macabí, } \\
\text { borrigero }\end{array}$ & $1,2,3$ & $\mathrm{Co}^{*}$ \\
\hline \multicolumn{5}{|l|}{ Anguilliformes } \\
\hline Muraenesocidae & $\begin{array}{c}\text { Cynoponticus } \\
\text { coniceps } \\
\text { (Jordan y } \\
\text { Gilbert, 1882) }\end{array}$ & $\begin{array}{c}\text { Zafiro, } \\
\text { congrio, } \\
\text { morena }\end{array}$ & $1,2,5,6,7$ & $\mathrm{Co}^{* *}$ \\
\hline \multicolumn{5}{|l|}{ Clupeiformes } \\
\hline \multirow[t]{2}{*}{ Pristigasteridae } & $\begin{array}{c}\text { Ilisha fuerthii } \\
\text { (Steindachner, } \\
\text { 1875)+ }\end{array}$ & $\begin{array}{c}\text { Sardina } \\
\text { hacha, } \\
\text { machete }\end{array}$ & $1,2,3,5$ & $\mathrm{Co}^{*}$ \\
\hline & $\begin{array}{c}\text { Odontognathus } \\
\text { panamensis } \\
\text { (Steindachner, } \\
1876)+\end{array}$ & $\begin{array}{l}\text { Sardina } \\
\text { machete, } \\
\text { machete }\end{array}$ & 2,5 & $\mathrm{Co}^{*}$ \\
\hline Engraulidae & $\begin{array}{c}\text { Cetengraulis } \\
\text { mysticetus } \\
\text { (Günther, 1867) }\end{array}$ & $\begin{array}{c}\text { Anchoveta, } \\
\text { sardina } \\
\text { agallona }\end{array}$ & 1 a 7 & $\mathrm{Co}^{* *}$ \\
\hline
\end{tabular}




\begin{tabular}{|c|c|c|c|c|}
\hline Orden/Familia & $\begin{array}{c}\text { Nombre } \\
\text { científico - } \\
\text { Autoridad [ ] } \\
\end{array}$ & $\begin{array}{l}\text { Nombre } \\
\text { común }\end{array}$ & Referencias & Obs. \\
\hline \multirow[t]{4}{*}{ Clupeidae } & $\begin{array}{c}\text { Opisthonema } \\
\text { bulleri } \\
\text { (Regan, 1904) }\end{array}$ & $\begin{array}{c}\text { Arenque, } \\
\text { arenque } \\
\text { bolillo }\end{array}$ & 4,6 & $\mathrm{Co}^{*}$ \\
\hline & $\begin{array}{c}\text { Opisthonema } \\
\text { libertate } \\
\text { (Günther, 1867) }\end{array}$ & $\begin{array}{c}\text { Arenque, } \\
\text { arenque de } \\
\text { hebra, } \\
\text { sardina, } \\
\text { arenca }\end{array}$ & 1 a 7 & $\mathrm{Co}^{* *}$ \\
\hline & $\begin{array}{c}\text { Opisthonema } \\
\text { medirastre } \\
\text { Berry y Barrett, } \\
1963+\end{array}$ & $\begin{array}{c}\text { Arenque, } \\
\text { sardina } \\
\text { machete, } \\
\text { arenque de } \\
\text { hebra }\end{array}$ & $2,4,5,6$ & $\mathrm{Co}^{* *}$ \\
\hline & $\begin{array}{c}\text { Opisthopterus } \\
\text { dovii } \\
\text { (Günter, 1868) }\end{array}$ & $\begin{array}{l}\text { Sardina } \\
\text { peorra, } \\
\text { sardina } \\
\text { chata, } \\
\text { macabí }\end{array}$ & $2,5,6$ & $\mathrm{Co}^{* *}$ \\
\hline \multicolumn{5}{|l|}{ Siluriformes } \\
\hline \multirow[t]{4}{*}{ Ariidae } & $\begin{array}{c}\text { Ariopsis } \\
\text { seemanni } \\
\text { (Günther, } \\
1864)+ \\
\end{array}$ & Bagre & 5,7 & $\mathrm{Co}^{*}$ \\
\hline & $\begin{array}{c}\text { Bagre } \\
\text { panamensis } \\
\text { (Gill, 1863) }\end{array}$ & $\begin{array}{l}\text { Congro, } \\
\text { bagre, } \\
\text { barbudo }\end{array}$ & 2,6 & $\mathrm{Co}^{*}$ \\
\hline & $\begin{array}{c}\text { Bagre } \\
\text { pinnimaculatus } \\
\text { (Steindachner, } \\
\text { 1876) }\end{array}$ & $\begin{array}{l}\text { Alguacil, } \\
\text { barbudo, } \\
\text { bagre, negro } \\
\text { en cuero }\end{array}$ & $1,2,3,5,6,7$ & $\mathrm{Co}^{* *}$ \\
\hline & $\begin{array}{c}\text { Cathorops } \\
\text { steindachneri } \\
\text { (Gilbert y } \\
\text { Starks, 1904) }\end{array}$ & $\begin{array}{l}\text { Congo, } \\
\text { cominata }\end{array}$ & 6 & $\mathrm{Co}^{*}$ \\
\hline
\end{tabular}




\begin{tabular}{|c|c|c|c|c|}
\hline Orden/Familia & $\begin{array}{c}\text { Nombre } \\
\text { científico - } \\
\text { Autoridad [ ] }\end{array}$ & $\begin{array}{l}\text { Nombre } \\
\text { común }\end{array}$ & Referencias & Obs. \\
\hline & $\begin{array}{c}\text { Notarius } \\
\text { kessleri } \\
\text { (Steindachner, } \\
1876)^{*}\end{array}$ & Cominate & 2 & $\mathrm{Co}^{*}$ \\
\hline & $\begin{array}{c}\text { Notarius } \\
\text { lentiginosus } \\
\text { (Eigenmann y } \\
\text { Eigenmann, } \\
1888 \text { )* } \\
\end{array}$ & Cominate & 7 & $\mathrm{Co}^{*}$ \\
\hline & $\begin{array}{c}\text { Notarius } \\
\text { troschelii } \\
\text { (Gill, 1863) }\end{array}$ & $\begin{array}{l}\text { Congo, } \\
\text { cominata }\end{array}$ & 6 & $\mathrm{Co}^{*}$ \\
\hline & $\begin{array}{c}\text { Occidentarius } \\
\text { platypogon } \\
\text { (Günther, 1864) }\end{array}$ & $\begin{array}{l}\text { Bagre, } \\
\text { cuminate, } \\
\text { cominate, } \\
\text { cominata }\end{array}$ & $1,2,3,5,6$ & $\mathrm{Co}^{* *}$ \\
\hline \multicolumn{5}{|l|}{ Ophidiiformes } \\
\hline \multirow[t]{2}{*}{ Ophidiidae } & $\begin{array}{c}\text { Brotula } \\
\text { clarkae } \\
\text { Hubbs, } 1944+\end{array}$ & $\begin{array}{l}\text { Congrio } \\
\text { rosado, } \\
\text { merluza }\end{array}$ & 6 & $\mathrm{Co}^{*}$ \\
\hline & $\begin{array}{c}\text { Brotula } \\
\text { ordwayi } \\
\text { Hildebrand y } \\
\text { Barton, 1949+ }\end{array}$ & $\begin{array}{l}\text { Congrio } \\
\text { pintado }\end{array}$ & 6 & $\mathrm{Co}^{*}$ \\
\hline \multicolumn{5}{|l|}{ Mugiliformes } \\
\hline \multirow[t]{2}{*}{ Mugilidae } & $\begin{array}{c}\text { Mugil } \\
\text { cephalus L., } \\
1758+ \\
{[\mathrm{P}, \mathrm{C}]}\end{array}$ & Lisa & $1,2,3,6$ & $\mathrm{Co}^{* *}$ \\
\hline & $\begin{array}{c}\text { Mugil } \\
\text { curema } \\
\text { Valenciennes, } \\
1836+\end{array}$ & $\begin{array}{c}\text { Lisa, corvina } \\
\text { lisa }\end{array}$ & $1,2,3,5,6,7$ & $\mathrm{Co}^{* *}$ \\
\hline
\end{tabular}




\begin{tabular}{|c|c|c|c|c|}
\hline Orden/Familia & $\begin{array}{c}\text { Nombre } \\
\text { científico - } \\
\text { Autoridad [ ] }\end{array}$ & $\begin{array}{l}\text { Nombre } \\
\text { común }\end{array}$ & Referencias & Obs. \\
\hline \multicolumn{5}{|l|}{ Beloniformes } \\
\hline \multirow[t]{2}{*}{ Belonidae } & $\begin{array}{c}\text { Tylosurus } \\
\text { fodiator } \\
\text { Jordan y } \\
\text { Gilbert, 1882* }\end{array}$ & $\begin{array}{l}\text { Aguja, } \\
\text { picudo }\end{array}$ & $1,2,3,5,6$ & $\mathrm{Co}^{* *}$ \\
\hline & $\begin{array}{c}\text { Tylosurus } \\
\text { pacificus } \\
\text { (Steindachner, } \\
1876)\end{array}$ & Aguja & 6 & $\mathrm{Co}^{*}$ \\
\hline \multicolumn{5}{|l|}{ Carangiformes } \\
\hline Nematistiidae & $\begin{array}{c}\text { Nematistius } \\
\text { pectoralis } \\
\text { Gill, 1862+ }\end{array}$ & $\begin{array}{l}\text { Pez gallo, } \\
\text { peje gallo }\end{array}$ & 1 a 7 & $\mathrm{Co}^{* *}$ \\
\hline Coryphaenidae & $\begin{array}{c}\text { Coryphaena } \\
\text { hippurus } \\
\mathrm{L} ., 1758+ \\
{[\mathrm{P}, \mathrm{C}]}\end{array}$ & Dorado & 1 a 7 & $\mathrm{Co}^{* *}$ \\
\hline \multirow[t]{5}{*}{ Carangidae } & $\begin{array}{c}\text { Alectis ciliaris } \\
\text { (Bloch, 1787) } \\
{[\mathrm{P}, \mathrm{C}]}\end{array}$ & $\begin{array}{c}\text { Caballito, } \\
\text { pámpano } \\
\text { africano }\end{array}$ & $1,2,3,4,6$ & $\mathrm{Co}^{* *}$ \\
\hline & $\begin{array}{c}\text { Carangoides } \\
\text { otrynter } \\
\text { (Jordan y } \\
\text { Gilbert, 1883) }\end{array}$ & $\begin{array}{l}\text { Luna, } \\
\text { pámpano }\end{array}$ & $2,5,6$ & $\mathrm{Co}^{* *}$ \\
\hline & $\begin{array}{c}\text { Caranx } \\
\text { caballus } \\
\text { Günther, } 1868+\end{array}$ & $\begin{array}{l}\text { Cojinúa, } \\
\text { cojinúa chata }\end{array}$ & $1,2,3,5,6,7$ & $\mathrm{Co}^{* *}$ \\
\hline & $\begin{array}{l}\text { Caranx caninus } \\
\text { Günther, } 1867+\end{array}$ & $\begin{array}{c}\text { Jurel, } \\
\text { jurelito, } \\
\text { chumbo, } \\
\text { cocinero }\end{array}$ & 1 a 7 & $\mathrm{Co}^{* *}$ \\
\hline & $\begin{array}{c}\text { Caranx } \\
\text { lugubris Poey, } \\
1860+ \\
{[\mathrm{P}, \mathrm{C}]}\end{array}$ & Jurel negro & 6 & $\mathrm{Co}^{*}$ \\
\hline
\end{tabular}




\begin{tabular}{|c|c|c|c|c|}
\hline Orden/Familia & $\begin{array}{c}\text { Nombre } \\
\text { científico - } \\
\text { Autoridad [ ] }\end{array}$ & $\begin{array}{l}\text { Nombre } \\
\text { común }\end{array}$ & Referencias & Obs. \\
\hline & $\begin{array}{c}\text { Caranx } \\
\text { melampygus } \\
\text { Cuvier, } 1833+ \\
\end{array}$ & Jurel azul & $4,5,6$ & $\mathrm{Co}^{* *}$ \\
\hline & $\begin{array}{c}\text { Caranx } \\
\text { sexfasciatus } \\
\text { Quoy y } \\
\text { Gaimard, } \\
1825+ \\
\end{array}$ & $\begin{array}{l}\text { Jurel ojón, } \\
\text { jurel } \\
\text { ojigordo }\end{array}$ & $4,5,6$ & $\mathrm{Co}^{* *}$ \\
\hline & $\begin{array}{c}\text { Caranx vinctus } \\
\text { Jordan y } \\
\text { Gilbert, } 1882+\end{array}$ & $\begin{array}{l}\text { Cojinúa } \\
\text { rayada }\end{array}$ & $2,5,7$ & $\mathrm{Co}^{* *}$ \\
\hline & $\begin{array}{c}\text { Chloroscombru } \\
\text { s orqueta } \\
\text { Jordan y } \\
\text { Gilbert, 1883+ }\end{array}$ & $\begin{array}{l}\text { Orqueta, } \\
\text { catarnica, } \\
\text { ojona }\end{array}$ & $1,2,3,4,6$ & $\mathrm{Co}^{* *}$ \\
\hline & $\begin{array}{c}\text { Decapterus } \\
\text { macarellus } \\
\text { (Cuvier, 1833) }\end{array}$ & Macarela & 6 & $\mathrm{Co}^{*}$ \\
\hline & $\begin{array}{c}\text { Decapterus } \\
\text { macrosoma } \\
\text { Bleeker, 1851+ }\end{array}$ & $\begin{array}{l}\text { Jurel chato, } \\
\text { cojinua chata }\end{array}$ & 2 & $\mathrm{Co}^{*}$ \\
\hline & $\begin{array}{c}\text { Elagatis } \\
\text { bipinnulata } \\
\text { (Quoy y } \\
\text { Gaimard, 1825) } \\
{[\mathrm{P}, \mathrm{C}]} \\
\end{array}$ & $\begin{array}{l}\text { Salmón, } \\
\text { salmonete }\end{array}$ & $1,2,5,6,7$ & $\mathrm{Co}^{* *}$ \\
\hline & $\begin{array}{c}\text { Gnathanodon } \\
\text { speciosus } \\
\text { (Forsskål, } \\
1775 \text { ) } \\
\end{array}$ & $\begin{array}{c}\text { Boquipenda, } \\
\text { pámpano } \\
\text { rayado }\end{array}$ & 1 a 7 & $\mathrm{Co}^{* *}$ \\
\hline & $\begin{array}{c}\text { Hemicaranx } \\
\text { leucurus } \\
\text { (Günther, 1864) }\end{array}$ & $\begin{array}{c}\text { Jurelito } \\
\text { aletiamarilla }\end{array}$ & $2,5,6$ & $\mathrm{Co}^{* *}$ \\
\hline
\end{tabular}




\begin{tabular}{|c|c|c|c|c|}
\hline Orden/Familia & $\begin{array}{c}\text { Nombre } \\
\text { científico - } \\
\text { Autoridad [ ] }\end{array}$ & $\begin{array}{l}\text { Nombre } \\
\text { común }\end{array}$ & Referencias & Obs. \\
\hline & $\begin{array}{c}\text { Hemicaranx } \\
\text { zelotes Gilbert, } \\
1898+ \\
\end{array}$ & $\begin{array}{l}\text { Cojinúa } \\
\text { chata negra }\end{array}$ & $1,2,5$ & $\mathrm{Co}^{*}$ \\
\hline & $\begin{array}{c}\text { Oligoplites } \\
\text { altus (Günther, } \\
1868 \text { ) }\end{array}$ & $\begin{array}{c}\text { Longino, } \\
\text { Aguirre } \\
\text { amarillo } \\
\end{array}$ & $2,3,5,6,7$ & $\mathrm{Co}^{* *}$ \\
\hline & $\begin{array}{l}\text { Oligoplites } \\
\text { refulgens } \\
\text { Gilbert y } \\
\text { Starks, 1904+ }\end{array}$ & $\begin{array}{c}\text { Longino, } \\
\text { macarela } \\
\text { cuerrua, } \\
\text { cuero } \\
\text { coliamarillo }\end{array}$ & $2,5,6$ & $\mathrm{Co}^{* *}$ \\
\hline & $\begin{array}{l}\text { Oligoplites } \\
\text { saurus } \\
\text { (Bloch y } \\
\text { Schneider, } \\
\text { 1801) }\end{array}$ & $\begin{array}{l}\text { Longino, } \\
\text { macarela }\end{array}$ & $2,5,6$ & $\mathrm{Co}^{* *}$ \\
\hline & $\begin{array}{c}\text { Selar } \\
\text { crumenophthal } \\
\text { mus } \\
\text { (Bloch, 1793) }\end{array}$ & $\begin{array}{l}\text { Cojinúa } \\
\text { ojona, ojón }\end{array}$ & $2,3,6,7$ & $\mathrm{Co}^{* *}$ \\
\hline & $\begin{array}{c}\text { Selene } \\
\text { brevoortii } \\
\text { (Gill, 1863) }\end{array}$ & $\begin{array}{l}\text { Cojinúa, } \\
\text { Adolfito }\end{array}$ & $1,2,3,5,6$ & $\mathrm{Co}^{* *}$ \\
\hline & $\begin{array}{l}\text { Selene orstedii } \\
\text { Lütken, } 1880+\end{array}$ & $\begin{array}{c}\text { Palometa } \\
\text { espejo }\end{array}$ & $2,3,5$ & $\mathrm{Co}^{*}$ \\
\hline & $\begin{array}{c}\text { Selene } \\
\text { peruviana } \\
\text { (Guichenot, } \\
\text { 1866)+ }\end{array}$ & Caballito & $1,2,3,5,7$ & $\mathrm{Co}^{*}$ \\
\hline & $\begin{array}{c}\text { Seriola lalandi } \\
\text { Valenciennes, } \\
1833^{*} \\
{[\mathrm{P}, \mathrm{C}]}\end{array}$ & Bojalá & 3 & $\mathrm{Co}^{*}$ \\
\hline & $\begin{array}{c}\text { Seriola peruana } \\
\text { Steindachner, } \\
1881+\end{array}$ & Cojinua & $2,3,5,6$ & $\mathrm{Co}^{* *}$ \\
\hline
\end{tabular}




\begin{tabular}{|c|c|c|c|c|}
\hline Orden/Familia & $\begin{array}{c}\text { Nombre } \\
\text { científico - } \\
\text { Autoridad [ ] }\end{array}$ & $\begin{array}{l}\text { Nombre } \\
\text { común }\end{array}$ & Referencias & Obs. \\
\hline & $\begin{array}{c}\text { Seriola } \\
\text { rivoliana } \\
\text { Valenciennes, } \\
1833+ \\
{[\mathrm{P}, \mathrm{C}]} \\
\end{array}$ & Bojalá & $2,3,4,5,6$ & $\mathrm{Co}^{* *}$ \\
\hline & $\begin{array}{c}\text { Trachinotus } \\
\text { kennedyi } \\
\text { Steindachner, } \\
1876+\end{array}$ & Pámpano & $2,3,4,6,7$ & $\mathrm{Co}^{* *}$ \\
\hline & $\begin{array}{c}\text { Trachinotus } \\
\text { paitensis } \\
\text { Cuvier, 1832+ }\end{array}$ & $\begin{array}{l}\text { Pámpano, } \\
\text { gitano }\end{array}$ & 2 & $\mathrm{Co}^{*}$ \\
\hline & $\begin{array}{c}\text { Trachinotus } \\
\text { rhodopus } \\
\text { Gill, 1863+ } \\
\end{array}$ & Pámpano & $1,4,6$ & $\mathrm{Co}^{* *}$ \\
\hline \multicolumn{5}{|l|}{ Istiophoriformes } \\
\hline Sphyraenidae & $\begin{array}{c}\text { Sphyraena } \\
\text { ensis } \\
\text { Jordan y } \\
\text { Gilbert, 1882+ }\end{array}$ & $\begin{array}{l}\text { Barracuda, } \\
\text { picuda, } \\
\text { corvina } \\
\text { picuda }\end{array}$ & $1,2,3,6,7$ & $\mathrm{Co}^{* *}$ \\
\hline Xiphiidae & $\begin{array}{c}\text { Xiphias } \\
\text { gladius } \\
\text { L., } 1758+\end{array}$ & Pez espada & $2,3,4,6,7$ & $\mathrm{Co}^{*}$ \\
\hline \multirow[t]{3}{*}{ Istiophoridae } & $\begin{array}{c}\text { Istiompax } \\
\text { indica } \\
\text { (Cuvier, 1832) }\end{array}$ & Marlín negro & 4,6 & $\mathrm{Co}^{*}$ \\
\hline & $\begin{array}{c}\text { Istiophorus } \\
\text { platypterus } \\
\text { (Shaw, 1792) } \\
{[\mathrm{P}, \mathrm{C}]}\end{array}$ & Pez vela & $4,6,7$ & $\mathrm{Co}^{*}$ \\
\hline & $\begin{array}{c}\text { Kajikia } \\
\text { audax } \\
\text { (Philippi, 1887) }\end{array}$ & $\begin{array}{l}\text { Marlín } \\
\text { rayado }\end{array}$ & 4,6 & $\mathrm{Co}^{*}$ \\
\hline
\end{tabular}




\begin{tabular}{|c|c|c|c|c|}
\hline Orden/Familia & $\begin{array}{c}\text { Nombre } \\
\text { científico - } \\
\text { Autoridad [ ] }\end{array}$ & $\begin{array}{l}\text { Nombre } \\
\text { común }\end{array}$ & Referencias & Obs. \\
\hline & $\begin{array}{c}\text { Makaira } \\
\text { nigricans } \\
\text { Lacepède, } \\
1802+ \\
{[\mathrm{P}, \mathrm{C} ; \mathrm{VU}]}\end{array}$ & Marlín azul & 4,6 & $\mathrm{Co}^{*}$ \\
\hline & $\begin{array}{c}\text { Tetrapturus } \\
\text { angustirostris } \\
\text { Tanaka, 1915+ }\end{array}$ & $\begin{array}{c}\text { Pez lanceta, } \\
\text { pez aguja } \\
\text { corta } \\
\end{array}$ & 4,6 & $\mathrm{Co}^{*}$ \\
\hline \multicolumn{5}{|l|}{ Pleuronectiformes } \\
\hline \multirow[t]{7}{*}{ Paralichthyidae } & $\begin{array}{c}\text { Ancylopsetta } \\
\text { dendritica } \\
\text { Gilbert, 1890* }\end{array}$ & $\begin{array}{l}\text { Lenguado, } \\
\text { boca abajo }\end{array}$ & 1,2 & $\mathrm{Co}^{*}$ \\
\hline & $\begin{array}{c}\text { Citharichthys } \\
\text { gilberti } \\
\text { Jenkins y } \\
\text { Evermann, } \\
1889+ \\
\end{array}$ & $\begin{array}{l}\text { Lenguado, } \\
\text { lenguado } \\
\text { boca grande }\end{array}$ & 2,5 & $\mathrm{Co}^{*}$ \\
\hline & $\begin{array}{c}\text { Citharichthys } \\
\text { platophrys } \\
\text { Gilbert, 1891+ }\end{array}$ & $\begin{array}{l}\text { Lenguado, } \\
\text { lenguado } \\
\text { frentón } \\
\end{array}$ & 2,5 & $\mathrm{Co}^{*}$ \\
\hline & $\begin{array}{c}\text { Cyclopsetta } \\
\text { panamensis } \\
\text { (Steindachner, } \\
1876)+\end{array}$ & $\begin{array}{c}\text { Lenguado, } \\
\text { lenguado } \\
\text { boca de Dios }\end{array}$ & $2,5,7$ & $\mathrm{Co}^{* *}$ \\
\hline & $\begin{array}{c}\text { Cyclopsetta } \\
\text { querna } \\
\text { (Jordan y } \\
\text { Bollman, } \\
\text { 1890)+ }\end{array}$ & $\begin{array}{l}\text { Lenguado, } \\
\text { lenguado } \\
\text { dientón }\end{array}$ & $2,5,7$ & $\mathrm{Co}^{*}$ \\
\hline & $\begin{array}{c}\text { Etropus } \\
\text { crossotus } \\
\text { Jordan y } \\
\text { Gilbert, 1882+ }\end{array}$ & $\begin{array}{l}\text { Lenguado, } \\
\text { lenguado } \\
\text { boca chica }\end{array}$ & 2,5 & $\mathrm{Co}^{* *}$ \\
\hline & $\begin{array}{l}\text { Hippoglossina } \\
\text { bollmani } \\
\text { Gilbert, } 1890+\end{array}$ & $\begin{array}{l}\text { Lenguado, } \\
\text { lenguado } \\
\text { pintado }\end{array}$ & 2,5 & $\mathrm{Co}^{*}$ \\
\hline
\end{tabular}




\begin{tabular}{|c|c|c|c|c|}
\hline \multirow[t]{2}{*}{ Orden/Familia } & $\begin{array}{c}\text { Nombre } \\
\text { científico - } \\
\text { Autoridad [ ] }\end{array}$ & $\begin{array}{l}\text { Nombre } \\
\text { común }\end{array}$ & Referencias & Obs. \\
\hline & $\begin{array}{c}\text { Hippoglossina } \\
\text { macrops } \\
\text { Steindachner, } \\
1876+\end{array}$ & $\begin{array}{c}\text { Lenguado, } \\
\text { lenguado } \\
\text { ojos grandes }\end{array}$ & 5 & $\mathrm{Co}^{*}$ \\
\hline \multicolumn{5}{|l|}{ Scombriformes } \\
\hline \multirow[t]{6}{*}{ Scombridae } & $\begin{array}{c}\text { Acanthocybium } \\
\text { solandri } \\
\text { (Cuvier, 1832) } \\
{[\mathrm{P}, \mathrm{C}]}\end{array}$ & $\begin{array}{c}\text { Guajú, } \\
\text { wahoo, peto } \\
\text { wahoo, peto }\end{array}$ & $2,4,5,6,7$ & $\mathrm{Co}^{* *}$ \\
\hline & $\begin{array}{c}\text { Auxis } \\
\text { thazard } \\
\text { (Lacepède, } \\
1800)^{*} \\
{[\mathrm{P}, \mathrm{C}]}\end{array}$ & $\begin{array}{c}\text { Guanco } \\
\text { negro }\end{array}$ & 5 & $\mathrm{Co}^{*}$ \\
\hline & $\begin{array}{c}\text { Euthynnus } \\
\text { lineatus } \\
\text { Kishinouye, } \\
1920+\end{array}$ & $\begin{array}{c}\text { Guanco } \\
\text { blanco, } \\
\text { barrilete } \\
\text { negro }\end{array}$ & $5,6,7$ & $\mathrm{Co}^{* *}$ \\
\hline & $\begin{array}{c}\text { Katsuwonus } \\
\text { pelamis } \\
\text { (L., 1758) }\end{array}$ & $\begin{array}{c}\text { Barrilete } \\
\text { negro, } \\
\text { guanco } \\
\text { negro, } \\
\text { barrilete } \\
\text { listado }\end{array}$ & 1 a 7 & $\mathrm{Co}^{* *}$ \\
\hline & $\begin{array}{l}\text { Sarda orientalis } \\
\text { (Temminck y } \\
\text { Schlegel, 1844) }\end{array}$ & $\begin{array}{l}\text { Bonito, } \\
\text { albacora }\end{array}$ & $2,4,5,6,7$ & $\mathrm{Co}^{* *}$ \\
\hline & $\begin{array}{c}\text { Scomber } \\
\text { japonicus } \\
\text { Houttuyn, } \\
1782+\end{array}$ & Bolillo & 2 & $\mathrm{Co}^{*}$ \\
\hline
\end{tabular}




\begin{tabular}{|c|c|c|c|c|}
\hline Orden/Familia & $\begin{array}{c}\text { Nombre } \\
\text { científico - } \\
\text { Autoridad [ ] } \\
\end{array}$ & $\begin{array}{l}\text { Nombre } \\
\text { común }\end{array}$ & Referencias & Obs. \\
\hline & $\begin{array}{c}\text { Scomberomoru } \\
\text { s sierra } \\
\text { Jordan y Starks, } \\
1895+\end{array}$ & Sierra & $2,5,6,7$ & $\mathrm{Co}^{* *}$ \\
\hline & $\begin{array}{c}\text { Thunnus } \\
\text { albacares } \\
\text { (Bonnaterre, } \\
\text { 1788) }\end{array}$ & $\begin{array}{l}\text { Atún aleta } \\
\text { amarilla }\end{array}$ & 1 a 7 & $\mathrm{Co}^{* *}$ \\
\hline \multirow[t]{2}{*}{ Stromateidae } & $\begin{array}{l}\text { Prepilus medius } \\
\text { (Peters, 1869)+ }\end{array}$ & $\begin{array}{l}\text { Pajarita, } \\
\text { palometa, } \\
\text { pampanita }\end{array}$ & $1,2,3,5$ & $\mathrm{Co}^{*}$ \\
\hline & $\begin{array}{c}\text { Prepilus } \\
\text { snyderi Gilbert } \\
\text { y Starks, 1904+ }\end{array}$ & $\begin{array}{l}\text { Pampanito } \\
\text { aleta corta, } \\
\text { palometa, } \\
\text { pampanita }\end{array}$ & 2,5 & $\mathrm{Co}^{*}$ \\
\hline \multicolumn{5}{|l|}{ Labriformes } \\
\hline \multirow[t]{4}{*}{ Scaridae } & $\begin{array}{c}\text { Scarus } \\
\text { compressus } \\
\text { (Osburn y } \\
\text { Nichols, 1916)* }\end{array}$ & Loro & 6,7 & $\mathrm{Co}^{*}$ \\
\hline & $\begin{array}{l}\text { Scarus ghobban } \\
\text { Forsskål, 1775+ }\end{array}$ & $\begin{array}{l}\text { Loro, pez } \\
\text { loro, loro } \\
\text { barbazul }\end{array}$ & $1,2,3,5,6,7$ & $\mathrm{Co}^{* *}$ \\
\hline & $\begin{array}{c}\text { Scarus perrico } \\
\text { Jordan y } \\
\text { Gilbert, } 1882+\end{array}$ & $\begin{array}{l}\text { Loro, loro } \\
\text { jorobado, } \\
\text { loro frentón }\end{array}$ & 5,6 & $\mathrm{Co}^{*}$ \\
\hline & $\begin{array}{c}\text { Scarus } \\
\text { rubroviolaceus } \\
\text { Bleeker, } 1847^{*}\end{array}$ & $\begin{array}{l}\text { Loro, loro } \\
\text { bicolor }\end{array}$ & 5,6 & $\mathrm{Co}^{*}$ \\
\hline
\end{tabular}




\begin{tabular}{|c|c|c|c|c|}
\hline Orden/Familia & $\begin{array}{c}\text { Nombre } \\
\text { científico - } \\
\text { Autoridad [ ] }\end{array}$ & $\begin{array}{l}\text { Nombre } \\
\text { común }\end{array}$ & Referencias & Obs. \\
\hline \multicolumn{5}{|l|}{ Perciformes } \\
\hline \multirow[t]{6}{*}{ Centropomidae } & $\begin{array}{c}\text { Centropomus } \\
\text { armatus } \\
\text { Gill, 1863+ }\end{array}$ & $\begin{array}{c}\text { Robalo, } \\
\text { gualajo, } \\
\text { robalo } \\
\text { armado }\end{array}$ & $1,2,3,5,6,7$ & $\mathrm{Co}^{* *}$ \\
\hline & $\begin{array}{c}\text { Centropomus } \\
\text { medius } \\
\text { Günther, } 1864+\end{array}$ & $\begin{array}{l}\text { Robalo, } \\
\text { gualajo } \\
\text { cariseco }\end{array}$ & 5,6 & $\mathrm{Co}^{*}$ \\
\hline & $\begin{array}{c}\text { Centropomus } \\
\text { nigrescens } \\
\text { Günther, } 1864+\end{array}$ & $\begin{array}{c}\text { Robalo, } \\
\text { robalo negro, } \\
\text { robalo } \\
\text { redondo }\end{array}$ & $2,4,5,6$ & $\mathrm{Co}^{* *}$ \\
\hline & $\begin{array}{c}\text { Centropomus } \\
\text { robalito } \\
\text { Jordan y } \\
\text { Gilbert, 1882+ }\end{array}$ & $\begin{array}{l}\text { Robalo, } \\
\text { robalo aleta } \\
\text { amarilla }\end{array}$ & $1,2,5,6$ & $\mathrm{Co}^{* *}$ \\
\hline & $\begin{array}{c}\text { Centropomus } \\
\text { unionensis } \\
\text { Bocourt, } 1868+\end{array}$ & $\begin{array}{c}\text { Robalo, } \\
\text { gualajo, } \\
\text { robalo chato, } \\
\text { gualazo }\end{array}$ & $1,2,3,5,6$ & $\mathrm{Co}^{* *}$ \\
\hline & $\begin{array}{c}\text { Centropomus } \\
\text { viridis } \\
\text { Lockington, } \\
1877+\end{array}$ & $\begin{array}{c}\text { Robalo, } \\
\text { robalo } \\
\text { blanco }\end{array}$ & $4,5,6,7$ & $\mathrm{Co}^{* *}$ \\
\hline Gerreidae & $\begin{array}{c}\text { Deckertichthys } \\
\text { aureolus } \\
\text { (Jordan y } \\
\text { Gilbert, 1882)* }\end{array}$ & $\begin{array}{c}\text { Mojarra, } \\
\text { mojarra } \\
\text { palometa }\end{array}$ & 5 & $\mathrm{Co}^{*}$ \\
\hline
\end{tabular}




\begin{tabular}{|c|c|c|c|c|}
\hline Orden/Familia & $\begin{array}{c}\text { Nombre } \\
\text { científico - } \\
\text { Autoridad [ ] }\end{array}$ & $\begin{array}{c}\text { Nombre } \\
\text { común }\end{array}$ & Referencias & Obs. \\
\hline & $\begin{array}{c}\text { Diapterus } \\
\text { peruvianus } \\
\text { (Cuvier, 1830) }\end{array}$ & $\begin{array}{l}\text { Mojarra, } \\
\text { mojarra } \\
\text { amarilla }\end{array}$ & $1,2,3,5,6,7$ & $\mathrm{Co}^{* *}$ \\
\hline & $\begin{array}{c}\text { Eucinostomus } \\
\text { currani } \\
\text { Zahuranec, } \\
1980+\end{array}$ & $\begin{array}{l}\text { Mojarra, } \\
\text { mojarra } \\
\text { tricolor }\end{array}$ & 5 & $\mathrm{Co}^{*}$ \\
\hline & $\begin{array}{c}\text { Eucinostomus } \\
\text { dowii } \\
(\mathrm{Gill}, 1863)+\end{array}$ & $\begin{array}{l}\text { Mojarra, } \\
\text { mojarra } \\
\text { manchita }\end{array}$ & 5 & $\mathrm{Co}^{*}$ \\
\hline & $\begin{array}{c}\text { Eucinostomus } \\
\text { gracilis } \\
(\mathrm{Gill}, 1862)+\end{array}$ & $\begin{array}{l}\text { Mojarra, } \\
\text { mojarra } \\
\text { delgada }\end{array}$ & 5 & $\mathrm{Co}^{*}$ \\
\hline & $\begin{array}{c}\text { Eugerres } \\
\text { brevimanus } \\
\text { (Günther, } \\
1864)+\end{array}$ & $\begin{array}{l}\text { Mojarra, } \\
\text { Palmito aleta } \\
\text { corta }\end{array}$ & 5 & $\mathrm{Co}^{*}$ \\
\hline & $\begin{array}{c}\text { Gerres } \\
\text { simillimus } \\
\text { Regan, 1907+ }\end{array}$ & $\begin{array}{c}\text { Mojarra, } \\
\text { mojarra } \\
\text { blanca }\end{array}$ & 5 & $\mathrm{Co}^{*}$ \\
\hline \multirow[t]{2}{*}{ Mullidae } & $\begin{array}{c}\text { Mulloidichthys } \\
\text { dentatus } \\
\text { (Gill, 1862) }\end{array}$ & Salmonete & 5 & $\mathrm{Co}^{*}$ \\
\hline & $\begin{array}{c}\text { Pseudupeneus } \\
\text { grandisquamis } \\
\text { (Gill, 1863)+ }\end{array}$ & $\begin{array}{l}\text { Salmonete } \\
\text { rosado }\end{array}$ & $1,2,5$ & $\mathrm{Co}^{*}$ \\
\hline
\end{tabular}




\begin{tabular}{|c|c|c|c|c|}
\hline Orden/Familia & $\begin{array}{c}\text { Nombre } \\
\text { científico - } \\
\text { Autoridad [ ] }\end{array}$ & $\begin{array}{l}\text { Nombre } \\
\text { común }\end{array}$ & Referencias & Obs. \\
\hline \multirow[t]{2}{*}{ Polynemidae } & $\begin{array}{c}\text { Polydactylus } \\
\text { approximans } \\
\text { (Lay y Bennett, } \\
1839)+\end{array}$ & Bobo blanco & $1,2,3,5,7$ & $\mathrm{Co}^{*}$ \\
\hline & $\begin{array}{c}\text { Polydactylus } \\
\text { opercularis } \\
(\text { Gill, 1863)+ }\end{array}$ & $\begin{array}{c}\text { Bobo } \\
\text { amarillo }\end{array}$ & $1,2,3,5,7$ & $\mathrm{Co}^{* *}$ \\
\hline \multirow[t]{3}{*}{ Kyphosidae } & $\begin{array}{c}\text { Kyphosus } \\
\text { elegans } \\
\text { (Peters, 1869) }\end{array}$ & Chopa & $1,3,5,6,7$ & $\mathrm{Co}^{* *}$ \\
\hline & $\begin{array}{c}\text { Kyphosus } \\
\text { ocyurus } \\
\text { (Jordan y } \\
\text { Gilbert, 1882) }\end{array}$ & $\begin{array}{l}\text { Salema, } \\
\text { salmón }\end{array}$ & $1,2,5,6,7$ & $\mathrm{Co}^{* *}$ \\
\hline & $\begin{array}{c}\text { Kyphosus } \\
\text { vaigiensis } \\
\text { (Quoy y } \\
\text { Gaimard, } \\
\text { 1825)* }\end{array}$ & $\begin{array}{c}\text { Chopa, } \\
\text { chopa rayada }\end{array}$ & 5,6 & $\mathrm{Co}^{* *}$ \\
\hline \multirow[t]{2}{*}{ Serranidae } & $\begin{array}{c}\text { Alphestes } \\
\text { immaculatus } \\
\text { Breder, 1936+ }\end{array}$ & $\begin{array}{c}\text { Guaseta } \\
\text { cherna }\end{array}$ & 5 & $\mathrm{Co}^{*}$ \\
\hline & $\begin{array}{c}\text { Alphestes } \\
\text { multiguttatus } \\
\text { (Günther, } \\
\text { 1867)+ }\end{array}$ & Perro & 4 & $\mathrm{Co}^{*}$ \\
\hline
\end{tabular}




\begin{tabular}{|c|c|c|c|c|}
\hline \multirow[t]{10}{*}{ Orden/Familia } & $\begin{array}{c}\text { Nombre } \\
\text { científico - } \\
\text { Autoridad [ ] }\end{array}$ & $\begin{array}{l}\text { Nombre } \\
\text { común }\end{array}$ & Referencias & Obs. \\
\hline & $\begin{array}{c}\text { Cephalopholis } \\
\text { panamensis } \\
\text { (Steindachner, } \\
\text { 1876)+ }\end{array}$ & $\begin{array}{c}\text { Cabrilla } \\
\text { panameña }\end{array}$ & $1,2,4,5$ & $\mathrm{Co}^{*}$ \\
\hline & $\begin{array}{c}\text { Diplectrum } \\
\text { pacificum Meek } \\
\text { e Hildebrand, } \\
1925+\end{array}$ & $\begin{array}{l}\text { Guabina de } \\
\text { piedra }\end{array}$ & 6 & $\mathrm{Co}^{*}$ \\
\hline & $\begin{array}{c}\text { Epinephelus } \\
\text { analogus Gill, } \\
1863+\end{array}$ & $\begin{array}{l}\text { Mero } \\
\text { pintado, } \\
\text { cabrilla } \\
\text { merete } \\
\end{array}$ & 1 a 7 & $\mathrm{Co}^{* *}$ \\
\hline & $\begin{array}{l}\text { Epinephelus } \\
\text { cifuentesi } \\
\text { Lavenberg y } \\
\text { Grove, 1993+ }\end{array}$ & $\begin{array}{c}\text { Cherna } \\
\text { mantequilla }\end{array}$ & 5 & $\mathrm{Co}^{*}$ \\
\hline & $\begin{array}{c}\text { Epinephelus } \\
\text { itajara } \\
\text { (Lichtenstein, } \\
\text { 1822)+ [P, C; } \\
\text { VU] }\end{array}$ & $\begin{array}{l}\text { Mero de } \\
\text { profundidad }\end{array}$ & $1,2,3,4,7$ & $\mathrm{Co}^{* *}$ \\
\hline & $\begin{array}{l}\text { Epinephelus } \\
\text { labriformis } \\
\text { (Jenyns, 1840) }\end{array}$ & $\begin{array}{l}\text { Cabrilla, } \\
\text { merete del } \\
\text { golfo }\end{array}$ & 5,6 & $\mathrm{Co}^{*}$ \\
\hline & $\begin{array}{c}\text { Epinephelus } \\
\text { quinquefasciatu } \\
s \text { (Bocourt, } \\
1868) \\
\end{array}$ & $\begin{array}{l}\text { Mero, mero } \\
\text { de } \\
\text { profundidad }\end{array}$ & $5,6,7$ & $\mathrm{Co}^{* *}$ \\
\hline & $\begin{array}{c}\text { Hemanthias } \\
\text { peruanus } \\
\text { (Steindachner, } \\
1875 \text { ) } \\
\end{array}$ & Doncella & 5,6 & $\mathrm{Co}^{*}$ \\
\hline & $\begin{array}{c}\text { Hemanthias } \\
\text { signifer } \\
\text { (Garman, 1899) }\end{array}$ & Doncella & 5,6 & $\mathrm{Co}^{*}$ \\
\hline
\end{tabular}




\begin{tabular}{|c|c|c|c|c|}
\hline Orden/Familia & $\begin{array}{c}\text { Nombre } \\
\text { científico - } \\
\text { Autoridad [ ] }\end{array}$ & $\begin{array}{l}\text { Nombre } \\
\text { común }\end{array}$ & Referencias & Obs. \\
\hline & $\begin{array}{c}\text { Hyporthodus } \\
\text { acanthistius } \\
\text { (Gilbert, 1892) } \\
\text { [VU] }\end{array}$ & $\begin{array}{c}\text { Cherna roja, } \\
\text { merete, } \\
\text { cherna } \\
\text { rosada }\end{array}$ & $2,4,5,6,7$ & $\mathrm{Co}^{* *}$ \\
\hline & $\begin{array}{l}\text { Hyporthodus } \\
\text { exsul } \\
\text { (Fowler, 1944) }\end{array}$ & $\begin{array}{c}\text { Cherna } \\
\text { pintada, } \\
\text { merete } \\
\text { pintado }\end{array}$ & 5,6 & $\mathrm{Co}^{*}$ \\
\hline & $\begin{array}{l}\text { Hyporthodus } \\
\text { niphobles } \\
\text { (Gilbert y } \\
\text { Starks, 1897) }\end{array}$ & Cherna gris & $4,5,6$ & $\mathrm{Co}^{*}$ \\
\hline & $\begin{array}{l}\text { Mycteroperca } \\
\text { xenarcha } \\
\text { Jordan, } 1888+\end{array}$ & $\begin{array}{l}\text { Cherna } \\
\text { escoba }\end{array}$ & $2,4,5,6$ & $\mathrm{Co}^{* *}$ \\
\hline & $\begin{array}{c}\text { Paralabrax } \\
\quad \text { loro } \\
\text { Walford, 1936+ }\end{array}$ & $\begin{array}{c}\text { Cabrilla loro, } \\
\text { cabrilla } \\
\text { roquera }\end{array}$ & 5,7 & $\mathrm{Co}^{*}$ \\
\hline & $\begin{array}{c}\text { Paranthias } \\
\text { colonus } \\
\text { (Valenciennes, } \\
1846)\end{array}$ & Barbero & 6 & $\mathrm{Co}^{*}$ \\
\hline Pomacanthidae & $\begin{array}{c}\text { Pomacanthus } \\
\text { zonipectus } \\
(\mathrm{Gill}, 1862)^{+}\end{array}$ & Pez ángel & 2 & $\mathrm{Co}^{*}$ \\
\hline Malacanthidae & $\begin{array}{l}\text { Caulolatilus } \\
\text { affinis Gill, } \\
1865+\end{array}$ & $\begin{array}{c}\text { Bacalao, } \\
\text { perica }\end{array}$ & 6 & $\mathrm{Co}^{*}$ \\
\hline Haemulidae & $\begin{array}{c}\text { Genyatremus } \\
\text { dovii } \\
\text { (Günther, } \\
\text { 1864)* }\end{array}$ & Rompepaila & $2,5,7$ & $\mathrm{Co}^{* *}$ \\
\hline
\end{tabular}




\begin{tabular}{|c|c|c|c|c|}
\hline Orden/Familia & $\begin{array}{c}\text { Nombre } \\
\text { científico - } \\
\text { Autoridad [ ] } \\
\end{array}$ & $\begin{array}{l}\text { Nombre } \\
\text { común }\end{array}$ & Referencias & Obs. \\
\hline & $\begin{array}{c}\text { Genyatremus } \\
\text { pacifici } \\
\text { (Günther, } \\
1864)^{*}\end{array}$ & Burro & $1,2,3,5,7$ & $\mathrm{Co}^{*}$ \\
\hline & $\begin{array}{c}\text { Haemulon } \\
\text { maculicauda } \\
\text { (Gill, 1862) }\end{array}$ & $\begin{array}{l}\text { Rompe paila, } \\
\text { frijolito, } \\
\text { brin, } \\
\text { soldadito }\end{array}$ & 6 & $\mathrm{Co}^{*}$ \\
\hline & $\begin{array}{l}\text { Haemulon } \\
\text { scudderii } \\
\text { Gill, 1862+ }\end{array}$ & $\begin{array}{l}\text { Rompe paila, } \\
\text { frijolito }\end{array}$ & 6 & $\mathrm{Co}^{*}$ \\
\hline & $\begin{array}{c}\text { Haemulon } \\
\text { sexfasciatum } \\
\text { Gill, 1862+ }\end{array}$ & Rompe paila & 6 & $\mathrm{Co}^{*}$ \\
\hline & $\begin{array}{c}\text { Haemulon } \\
\text { steindachneri } \\
\text { (Jordan y } \\
\text { Gilbert, 1882) }\end{array}$ & $\begin{array}{l}\text { Peje fondo, } \\
\text { frijolito }\end{array}$ & $2,5,6$ & $\mathrm{Co}^{* *}$ \\
\hline & $\begin{array}{c}\text { Haemulopsis } \\
\text { axillaris } \\
\text { (Steindachner, } \\
\text { 1869)* }\end{array}$ & Roncador & 2 & $\mathrm{Co}^{*}$ \\
\hline & $\begin{array}{c}\text { Haemulopsis } \\
\text { elongatus } \\
\text { (Steindachner, } \\
1879 \text { ) }\end{array}$ & Pargo bejuco & 6 & $\mathrm{Co}^{*}$ \\
\hline & $\begin{array}{c}\text { Haemulopsis } \\
\text { leuciscus } \\
\text { (Günther, 1864) }\end{array}$ & Cabezón & $1,2,6$ & $\mathrm{Co}^{* *}$ \\
\hline & $\begin{array}{c}\text { Microlepidotus } \\
\text { brevipinnis } \\
\text { (Steindachner, } \\
1869)^{*}\end{array}$ & Peje fondo & 1 & $\mathrm{Co}^{*}$ \\
\hline
\end{tabular}




\begin{tabular}{|c|c|c|c|c|}
\hline Orden/Familia & $\begin{array}{c}\text { Nombre } \\
\text { científico - } \\
\text { Autoridad [ ] }\end{array}$ & $\begin{array}{l}\text { Nombre } \\
\text { común }\end{array}$ & Referencias & Obs. \\
\hline & $\begin{array}{c}\text { Orthopristis } \\
\text { chalceus } \\
\text { (Günther, } \\
\text { 1864)+ }\end{array}$ & Puerquita & $1,2,3,5,7$ & $\mathrm{Co}^{* *}$ \\
\hline & $\begin{array}{c}\text { Pomadasys } \\
\text { branickii } \\
\text { (Steindachner, } \\
\text { 1879) }\end{array}$ & $\begin{array}{c}\text { Cabezón, } \\
\text { pargo blanco }\end{array}$ & 6 & $\mathrm{Co}^{*}$ \\
\hline & $\begin{array}{c}\text { Pomadasys } \\
\text { macracanthus } \\
\text { (Günther, 1864) }\end{array}$ & $\begin{array}{c}\text { Cabezón, } \\
\text { brin }\end{array}$ & 5,6 & $\mathrm{Co}^{*}$ \\
\hline & $\begin{array}{c}\text { Pomadasys } \\
\text { panamensis } \\
\text { (Steindachner, } \\
1876)\end{array}$ & $\begin{array}{c}\text { Pargo } \\
\text { blanco, } \\
\text { cabezón }\end{array}$ & $1,2,3,5,6,7$ & $\mathrm{Co}^{* *}$ \\
\hline \multirow[t]{4}{*}{ Lutjanidae } & $\begin{array}{c}\text { Hoplopagrus } \\
\text { guentherii } \\
\text { Gill, 1862+ }\end{array}$ & $\begin{array}{c}\text { Pargo } \\
\text { dientón, } \\
\text { pargo } \\
\text { cocorito, } \\
\text { rompe paila }\end{array}$ & $1,2,6$ & $\mathrm{Co}^{* *}$ \\
\hline & $\begin{array}{l}\text { Lutjanus aratus } \\
\text { (Günther, 1864) }\end{array}$ & $\begin{array}{c}\text { Pargo } \\
\text { jilguero, } \\
\text { silguero } \\
\end{array}$ & $2,3,4,5,6,7$ & $\mathrm{Co}^{* *}$ \\
\hline & $\begin{array}{c}\text { Lutjanus } \\
\text { argentiventris } \\
\text { (Peters, 1869) }\end{array}$ & $\begin{array}{c}\text { Pargo } \\
\text { amarillo, } \\
\text { pargo } \\
\text { rosquero }\end{array}$ & $1,2,3,4,6,7$ & $\mathrm{Co}^{* *}$ \\
\hline & $\begin{array}{c}\text { Lutjanus } \\
\text { colorado } \\
\text { Jordan y } \\
\text { Gilbert, 1882+ }\end{array}$ & $\begin{array}{l}\text { Pargo rojo, } \\
\text { silguero }\end{array}$ & $2,3,4,5,6,7$ & $\mathrm{Co}^{* *}$ \\
\hline
\end{tabular}




\begin{tabular}{|c|c|c|c|c|}
\hline Orden/Familia & $\begin{array}{c}\text { Nombre } \\
\text { científico - } \\
\text { Autoridad [ ] }\end{array}$ & $\begin{array}{l}\text { Nombre } \\
\text { común }\end{array}$ & Referencias & Obs. \\
\hline & $\begin{array}{c}\text { Lutjanus } \\
\text { guttatus } \\
\text { (Steindachner, } \\
\text { 1869) }\end{array}$ & $\begin{array}{c}\text { Pargo } \\
\text { mancha, } \\
\text { pargo de la } \\
\text { mancha }\end{array}$ & 1 a 7 & $\mathrm{Co}^{* *}$ \\
\hline & $\begin{array}{c}\text { Lutjanus } \\
\text { inermis } \\
\text { (Peters, 1869) }\end{array}$ & $\begin{array}{l}\text { Pargo jobero, } \\
\text { pargo fondo, } \\
\text { pargo vivian }\end{array}$ & $2,5,6$ & $\mathrm{Co}^{* *}$ \\
\hline & $\begin{array}{c}\text { Lutjanus } \\
\text { jordani } \\
\text { (Gilbert, 1898) }\end{array}$ & $\begin{array}{c}\text { Pargo } \\
\text { nanguero, } \\
\text { saltona }\end{array}$ & $1,2,3,5,6$ & $\mathrm{Co}^{* *}$ \\
\hline & $\begin{array}{c}\text { Lutjanus } \\
\text { novemfasciatus } \\
\text { Gill, 1862+ }\end{array}$ & $\begin{array}{c}\text { Pargo } \\
\text { dientón, } \\
\text { pargo negro }\end{array}$ & $2,3,4,5,6,7$ & $\mathrm{Co}^{* *}$ \\
\hline & $\begin{array}{l}\text { Lutjanus peru } \\
\text { (Nichols y } \\
\text { Murphy, 1922) }\end{array}$ & $\begin{array}{l}\text { Pargo seda, } \\
\text { pargo de } \\
\text { seda }\end{array}$ & $4,5,6,7$ & $\mathrm{Co}^{* *}$ \\
\hline & $\begin{array}{c}\text { Lutjanus viridis } \\
\text { (Valenciennes, } \\
1846)+ \\
{[\mathrm{P}, \mathrm{C}]}\end{array}$ & Pargo azul & 5 & $\mathrm{Co}^{*}$ \\
\hline \multicolumn{5}{|l|}{ Scorpaeniformes } \\
\hline \multirow[t]{3}{*}{ Triglidae } & $\begin{array}{c}\text { Prionotus } \\
\text { albirostris } \\
\text { Jordan y } \\
\text { Bollman, } \\
1890+\end{array}$ & $\begin{array}{c}\text { Cabro } \\
\text { cariblanco }\end{array}$ & 5 & $\mathrm{Co}^{*}$ \\
\hline & $\begin{array}{c}\text { Prionotus } \\
\text { horrens } \\
\text { Richardson, } \\
1844+\end{array}$ & $\begin{array}{c}\text { Mal armado, } \\
\text { mal armao, } \\
\text { torito }\end{array}$ & 2,3 & $\mathrm{Co}^{*}$ \\
\hline & $\begin{array}{c}\text { Prionotus } \\
\text { ruscarius } \\
\text { Gilbert y } \\
\text { Starks, 1904+ }\end{array}$ & $\begin{array}{c}\text { Mal armao, } \\
\text { torito }\end{array}$ & $2,3,5$ & $\mathrm{Co}^{*}$ \\
\hline
\end{tabular}




\begin{tabular}{|c|c|c|c|c|}
\hline Orden/Familia & $\begin{array}{c}\text { Nombre } \\
\text { científico - } \\
\text { Autoridad [ ] }\end{array}$ & $\begin{array}{l}\text { Nombre } \\
\text { común }\end{array}$ & Referencias & Obs. \\
\hline \multicolumn{5}{|l|}{ Moroniformes } \\
\hline \multirow[t]{2}{*}{ Ephippidae } & $\begin{array}{c}\text { Chaetodipterus } \\
\text { zonatus } \\
\text { (Girard, 1858)+ }\end{array}$ & $\begin{array}{l}\text { Pollera } \\
\text { rayada }\end{array}$ & $1,2,3,5,7$ & $\mathrm{Co}^{*}$ \\
\hline & $\begin{array}{c}\text { Parapsettus } \\
\text { panamensis } \\
\text { (Steindachner, } \\
\text { 1876)+ }\end{array}$ & $\begin{array}{c}\text { Pollera } \\
\text { panameña }\end{array}$ & $2,5,7$ & $\mathrm{Co}^{*}$ \\
\hline \multicolumn{5}{|l|}{ Acanthuriformes } \\
\hline \multirow[t]{6}{*}{ Sciaenidae } & $\begin{array}{c}\text { Bairdiella } \\
\text { armata } \\
\text { Gill, 1863+ }\end{array}$ & $\begin{array}{c}\text { Corvina } \\
\text { rabirrubia, } \\
\text { toliba, } \\
\text { curruca }\end{array}$ & 6 & $\mathrm{Co}^{*}$ \\
\hline & $\begin{array}{c}\text { Bairdiella } \\
\text { ensifera } \\
\text { Jordan y } \\
\text { Gilbert, 1882) }\end{array}$ & $\begin{array}{c}\text { Toliba, } \\
\text { corvina de } \\
\text { estero, } \\
\text { barbirrubia }\end{array}$ & 6 & $\mathrm{Co}^{*}$ \\
\hline & $\begin{array}{c}\text { Corvula } \\
\text { macrops } \\
\text { (Steindachner, } \\
1876)\end{array}$ & Cococha & 6 & $\mathrm{Co}^{*}$ \\
\hline & $\begin{array}{c}\text { Cynoscion } \\
\text { albus } \\
\text { (Günther, 1864) }\end{array}$ & $\begin{array}{l}\text { Corvina } \\
\text { blanca }\end{array}$ & $2,4,5,6,7$ & $\mathrm{Co}^{* *}$ \\
\hline & $\begin{array}{c}\text { Cynoscion } \\
\text { phoxocephalus } \\
\text { Jordan y } \\
\text { Gilbert, } 1882+\end{array}$ & $\begin{array}{l}\text { Corvina } \\
\text { rolliza, } \\
\text { corvina } \\
\text { blanca, } \\
\text { corvinilla }\end{array}$ & $1,2,3,5,6,7$ & $\mathrm{Co}^{* *}$ \\
\hline & $\begin{array}{c}\text { Cynoscion } \\
\text { praedatorius } \\
\text { (Jordan y } \\
\text { Gilbert, 1889) }\end{array}$ & $\begin{array}{l}\text { Corvina } \\
\text { bocona, } \\
\text { bocón }\end{array}$ & $2,3,5,6,7$ & $\mathrm{Co}^{* *}$ \\
\hline
\end{tabular}




\begin{tabular}{|c|c|c|c|c|}
\hline Orden/Familia & $\begin{array}{c}\text { Nombre } \\
\text { científico - } \\
\text { Autoridad [ ] }\end{array}$ & $\begin{array}{l}\text { Nombre } \\
\text { común }\end{array}$ & Referencias & Obs. \\
\hline & $\begin{array}{c}\text { Cynoscion } \\
\text { reticulatus } \\
\text { (Günther, 1864) }\end{array}$ & $\begin{array}{l}\text { Corvina } \\
\text { rayada, } \\
\text { herrero }\end{array}$ & $1,2,3,5,6,7$ & $\mathrm{Co}^{* *}$ \\
\hline & $\begin{array}{c}\text { Cynoscion } \\
\text { squamipinnis } \\
\text { (Günther, 1867) }\end{array}$ & $\begin{array}{l}\text { Corvina } \\
\text { pelona, } \\
\text { roncona, } \\
\text { chichera } \\
\end{array}$ & $1,2,3,5,6,7$ & $\mathrm{Co}^{* *}$ \\
\hline & $\begin{array}{c}\text { Cynoscion } \\
\text { stolzmanni } \\
\text { (Steindachner, } \\
1879 \text { ) } \\
\end{array}$ & $\begin{array}{c}\text { Corvina } \\
\text { coliamarilla, } \\
\text { corvina } \\
\text { amarilla } \\
\end{array}$ & 1 a 7 & $\mathrm{Co}^{* *}$ \\
\hline & $\begin{array}{c}\text { Elattarchus } \\
\text { archidium } \\
\text { (Jordan y } \\
\text { Gilbert, 1882)+ }\end{array}$ & Corvina & 2 & $\mathrm{Co}^{*}$ \\
\hline & $\begin{array}{l}\text { Isopisthus } \\
\text { remifer } \\
\text { Jordan y } \\
\text { Gilbert, 1882+ }\end{array}$ & $\begin{array}{c}\text { Corvina } \\
\text { mordedora, } \\
\text { corvina } \\
\text { ojona } \\
\end{array}$ & $2,5,6$ & $\mathrm{Co}^{* *}$ \\
\hline & $\begin{array}{c}\text { Larimus } \\
\text { acclivis } \\
\text { Jordan y } \\
\text { Bristol, 1898+ }\end{array}$ & $\begin{array}{l}\text { Corvina } \\
\text { boquituerta, } \\
\text { cirila roja }\end{array}$ & $2,3,5$ & $\mathrm{Co}^{*}$ \\
\hline & $\begin{array}{c}\text { Larimus } \\
\text { argenteus } \\
\text { (Gill, 1863) }\end{array}$ & $\begin{array}{c}\text { Corvina } \\
\text { boquituerta }\end{array}$ & $1,2,3,5,6$ & $\mathrm{Co}^{* *}$ \\
\hline & $\begin{array}{c}\text { Larimus } \\
\text { effulgens } \\
\text { Gilbert, } 1898\end{array}$ & $\begin{array}{c}\text { Corvina } \\
\text { boquituerta }\end{array}$ & $2,3,5$ & $\mathrm{Co}^{*}$ \\
\hline & $\begin{array}{l}\text { Macrodon } \\
\text { mordax } \\
\text { (Gilbert y } \\
\text { Starks, 1904) }\end{array}$ & $\begin{array}{l}\text { Corvina } \\
\text { mordedora, } \\
\text { corvina lona }\end{array}$ & $1,2,3,5,6,7$ & $\mathrm{Co}^{* *}$ \\
\hline
\end{tabular}




\begin{tabular}{|c|c|c|c|c|}
\hline Orden/Familia & $\begin{array}{c}\text { Nombre } \\
\text { científico - } \\
\text { Autoridad [ ] }\end{array}$ & $\begin{array}{l}\text { Nombre } \\
\text { común }\end{array}$ & Referencias & Obs. \\
\hline & $\begin{array}{c}\text { Menticirrhus } \\
\text { nasus } \\
\text { (Günther, 1868) }\end{array}$ & $\begin{array}{l}\text { Corvina de } \\
\text { piedra, } \\
\text { corvina } \\
\text { gallote }\end{array}$ & 6 & $\mathrm{Co}^{*}$ \\
\hline & $\begin{array}{c}\text { Menticirrhus } \\
\text { panamensis } \\
\text { (Steindachner, } \\
1876) \\
\end{array}$ & $\begin{array}{l}\text { Corvina de } \\
\text { piedra }\end{array}$ & $1,2,5,6,7$ & $\mathrm{Co}^{* *}$ \\
\hline & $\begin{array}{c}\text { Micropogonias } \\
\text { altipinnis } \\
\text { (Günther, 1864) }\end{array}$ & $\begin{array}{c}\text { Guabina de } \\
\text { piedra, } \\
\text { corvina lona }\end{array}$ & $1,2,3,5,6,7$ & $\mathrm{Co}^{* *}$ \\
\hline & $\begin{array}{c}\text { Micropogonias } \\
\text { furnieri } \\
\text { (Desmarest, } \\
1823 \text { )+ }\end{array}$ & Corvina lona & 1,2 & $\mathrm{Co}^{*}$ \\
\hline & $\begin{array}{c}\text { Nebris } \\
\text { occidentalis } \\
\text { Vaillant, 1897+ }\end{array}$ & $\begin{array}{l}\text { Guabina, } \\
\text { corvina } \\
\text { china }\end{array}$ & $1,2,3,5,6,7$ & $\mathrm{Co}^{* *}$ \\
\hline & $\begin{array}{c}\text { Ophioscion } \\
\text { scierus } \\
\text { (Jordan y } \\
\text { Gilbert, 1884) }\end{array}$ & $\begin{array}{l}\text { Corvina, } \\
\text { parita }\end{array}$ & 6 & $\mathrm{Co}^{*}$ \\
\hline & $\begin{array}{c}\text { Paralonchurus } \\
\text { dumerilii } \\
\text { (Bocourt, 1869) }\end{array}$ & $\begin{array}{c}\text { Sargento, } \\
\text { herrero }\end{array}$ & $2,5,6,7$ & $\mathrm{Co}^{* *}$ \\
\hline & $\begin{array}{c}\text { Paralonchurus } \\
\text { petersii } \\
\text { Bocourt, 1869+ }\end{array}$ & $\begin{array}{l}\text { Corvina de } \\
\text { piedra }\end{array}$ & 6 & $\mathrm{Co}^{*}$ \\
\hline & $\begin{array}{c}\text { Umbrina } \\
\text { dorsalis Gill, } \\
1862+\end{array}$ & $\begin{array}{c}\text { Corvina } \\
\text { negra, } \\
\text { verrugato } \\
\text { aleta larga }\end{array}$ & 1,5 & $\mathrm{Co}^{*}$ \\
\hline & $\begin{array}{c}\text { Umbrina xanti } \\
\text { (Gill, 1862) }\end{array}$ & $\begin{array}{l}\text { Corvina } \\
\text { rayada }\end{array}$ & 6 & $\mathrm{Co}^{*}$ \\
\hline
\end{tabular}




\begin{tabular}{|c|c|c|c|c|}
\hline Orden/Familia & $\begin{array}{c}\text { Nombre } \\
\text { científico - } \\
\text { Autoridad [ ] }\end{array}$ & $\begin{array}{l}\text { Nombre } \\
\text { común }\end{array}$ & Referencias & Obs. \\
\hline \multicolumn{5}{|l|}{ Spariformes } \\
\hline \multirow[t]{2}{*}{ Lobotidae } & $\begin{array}{c}\text { Lobotes } \\
\text { pacificus } \\
\text { Gilbert, } 1898+ \\
\end{array}$ & $\begin{array}{c}\text { Berrugate, } \\
\text { dormilón, } \\
\text { pargo negro }\end{array}$ & $1,2,3,5,6,7$ & $\mathrm{Co}^{* *}$ \\
\hline & $\begin{array}{c}\text { Lobotes } \\
\text { surinamensis } \\
(\mathrm{Bloch}, 1790)+ \\
{[\mathrm{P}, \mathrm{C}]}\end{array}$ & Berrugate & 1,2 & $\mathrm{Co}^{*}$ \\
\hline Sparidae & $\begin{array}{c}\text { Calamus } \\
\text { brachysomus } \\
\text { (Lockington, } \\
1880)\end{array}$ & Vaca, burro & 6 & $\mathrm{Co}^{*}$ \\
\hline \multicolumn{5}{|l|}{ Tetraodontiformes } \\
\hline Balistidae & $\begin{array}{c}\text { Balistes } \\
\text { polylepis } \\
\text { Steindachner, } \\
1876+\end{array}$ & $\begin{array}{l}\text { Catimba, } \\
\text { cachimbao, } \\
\text { pez puerco }\end{array}$ & 6,7 & $\mathrm{Co}^{*}$ \\
\hline
\end{tabular}

\section{CONCLUSIONES}

Los listados con las principales especies pesqueras de importancia comercial cuentan con registros válidos muy variables para el Pacífico de Panamá, a saber 86 especies (76 óseos), 144 especies (134 óseos) y 76 especies (73 óseos), respectivamente para MICI (1977), MICI (1992) y AMP (2005).

Se informan un total de 223 especies de peces de importancia comercial del Pacífico de Panamá correspondientes a 183 peces óseos y 40 cartilaginosos, las mismas se ubican en un total de 24 órdenes y 49 familias, siendo Carangidae (28), Sciaenidae (25) y Carcharhinidae (17) las más comunes y un total de 121 géneros siendo Carcharhinus spp. (11) y Lutjanus spp. (9) los más representados.

El listado actualiza en 205 los registros de peces de importancia comercial correspondientes para el Pacífico de Panamá, así como 130 
nombres científicos y/o autoridades a nivel local encontrándose 39 especies en alguna categoría de amenaza, principalmente tiburones y rayas, algunos picudos y peces loros.

A futuro esta base de datos debe ser fortalecida con información molecular que confirme la nomenclatura, nuevas especies e híbridos moleculares posiblemente existentes en aguas panameñas.

\section{AGRADECIMIENTOS}

Al Centro de Documentación del Centro de Ciencias del Mar y Limnología de la Universidad de Panamá (UP) por el material de referencia suministrado. Al Departamento de Biología Marina y Limnología (UP) por todo el apoyo para culminar esta investigación. Al Dr. Edgardo Díaz Fergurson (Coiba-AIP) por sus valiosos comentarios y revisión editorial.

\section{REFERENCIAS}

Allen, G.R. \& D.R. Robertson. (1998). Peces del Pacífico oriental tropical. 2a ed. trad. Sierra Madre, México, D.F.

AMP. 2005. Estadística pesquera comentada años 2000-2004. Dirección General de Recursos Marinos y Costeros. AMP, Panamá. ARAP. (2011). Guía para la identificación de peces de interés comercial para el Pacífico de Panamá. Dirección de Investigación y Desarrollo. Documento Técnico de Pesca. ARAP, Panamá.

ARAP. (2019a). Autoridad de Recursos Acuáticos de Panamá. Legislación.

http://arap.gob.pa/legislacion/

ARAP. (2019b). Autoridad de Recursos Acuáticos de Panamá. Fauna marina.

http://arap.gob.pa/unidad-ambiental/fauna-marina-2/ 
Arenas G., P. \& H. Garcés B. (2009). Diagnóstico de la gestión del litoral en la República de Panamá. En: Barragán M., J.M. (ed.). Manejo costero integrado y política Iberoamericana: un diagnóstico. Necesidad de cambio. Red IBERMAR (CYTED), Cádiz, pp 71-90.

Bussing, W.A. \& M.I. López. (2011). Peces demersales y pelágicos costeros del Pacífico de centro américa meridional. Guía ilustrada. / Demersal and pelagic inshore fishes of the Pacific coast of lower central america. An illustrated guide. Editorial Universidad de Costa Rica, San José.

Cisneros-Montemayor, A.M., S. Harper \& T.C. Tai. (2018). The market and shadow value of informal fish catch: a framework and application to Panama. Natural Resources Forum 42(2): 83-92.

CONTRALORÍA GENERAL DE LA REPÚBLICA. (2019). Instituto Nacional de Estadística y Censo. Panamá en cifras. http://www.contraloria.gob.pa/inec/Publicaciones/

Fischer, W., F. Krupp, W. Scheneider, C. Sommer, K.E. Carpenter \& V.H. Niem. (1995). Guía FAO para la identificación de especies para los fines de pesca. Pacífico centro-oriental. FAO, Roma.

FISHBASE. (2019). Catálogo mundial de peces. ver 12/19. http://www.fishbase.org/search.php

Garcés B., H.A. (2014). Actualización del diagnóstico de la gestión del litoral en la República de Panamá. Informe final Proyecto de investigación código VIP-01-04-00-10-2014-08. Universidad de Panamá, Panamá.

Garcés B., H.A. (2018). Lista actualizada de los principales peces comerciales del Mercado del Marisco, Panamá. Informe final. Proyecto de investigación código VIP-01-06-07-2016-04. Universidad de Panamá, Panamá. 
Garrison, G. (2005). Peces de la isla del Coco. / Isla del Coco fishes. INBIO, Santo Domingo de Heredia.

Justines A., G. (2000). Principales recursos pesqueros de Panamá: situación actual y proyección futura. Asociación Nacional de la Industria Pesquera Panameña. ANDELAIPP, Panamá.

MARVIVA. (2017). Peces de importancia comercial en la costa Pacífica de Panamá. Guía de identificación. Fundación MarViva, Panamá.

MARVIVA. (2019). MarViva: guía semáforo. Información en línea para android. v. 2.0.0. Fundación MarViva, Panamá.

https://play.google.com/store/apps/details?id=com.yunke.marvivaguia

$\underline{\text { \&hl=es } 419}$

Maté, J. (2007). Análisis de la situación de la pesca en los golfos de Chiriquí y de Montijo. 2a ed. reimp. TNC, Panamá.

Meneses, I. (2000). Análisis histórico e institucional del sector pesquero de Panamá. APRONAD, Panamá.

MIAMBIENTE. (2105). Ley No. 8 que crea el Ministerio de Ambiente, modifica disposiciones de la Autoridad de los Recursos Acuáticos de Panamá y dicta otras disposiciones. G.O. No. 27749-B, viernes 27 de marzo de (2015). MiAmbiente, Panamá.

MICI. 1977. Estadísticas pesqueras (1968 a 1977). Dirección General de Recursos Marinos. Ministerio de Comercio e Industrias, Panamá.

MICI. 1992. Estadística pesquera (1981 a 1990). Dirección General de Recursos Marinos. Ministerio de Comercio e Industrias, Panamá. 
Nelson, J.S., T.C. Grande \& M.V.H. Wilson. (2018). Fishes of the world 5. Additional resources. Detailed classification of all fishes. https://sites.google.com/site/fotw5th/

OSPESCA. (2012). Encuesta estructural de la pesca artesanal y la acuicultura en centroamérica 2009-2011. Organización del sector pesquero y acuícola del istmo centroamericano. OIRSA-OSPESCA, El Salvador.

Robertson, D.R. \& G.R. Allen. (2006). Peces costeros del Pacífico oriental tropical: un sistema de información. STRI, Panamá.

http://www.discoverlife.org/shorefish/index.spanish.html

Robertson, D.R. \& G.R. Allen. (2015). Peces costeros del Pacífico oriental tropical: sistema de información en línea. v. 2.0. STRI, Panamá.

http://biogeodb.stri.si.edu/sftep/es/pages

Robertson, D.R. \& G.R. Allen. (2016). Peces costeros del Pacífico oriental tropical: sistema de información en línea para app. v. 3.0.1. STRI, Panamá.

https://itunes.apple.com/mx/app/peces-pacificooriental $/ \mathrm{id} 494644648 ? \mathrm{mt}=8$

Valverde B., R.A. (2013). Producción y comercialización de la pesca artesanal o de pequeña escala en Panamá desde 1995 al 2008. Revista CENTROS 2(1): 115-131.

Recibido 20 mayo 2020, y aceptado 13 noviembre 2020 